\title{
Public space quality evaluation: prerequisite for public space management
}

\author{
Seema Praliya, Pushplata Garg \\ Indian Institute of Technology Roorkee, India \\ seemadap@iitr.ac.in | pushpfap@iitr.ac.in
}

\begin{abstract}
Public spaces are an important part of cities as they contribute to improvements in liveability, environmental quality and sustainability. Despite these conditions of public spaces in cities in developing countries like India, are far from desirable in terms of quantity as well as quality. Though considerable research has been done on successful public open spaces to identify quality attributes/criteria and their evaluation in the context of developed countries, much of this has been primarily aimed at providing design guidelines/solutions. Besides, the role of proper management in ensuring quality and overall success of public spaces has also been assessed. However, not much research has been done in this regard in Indian context, where there is a considerable difference between the norms and provision of public spaces; the usage of public spaces and their quality from those in developed/rich countries This demands an in-depth understanding of the problems and issues surrounding public spaces, the criteria for quality in public spaces, and development of an evaluation framework, so that appropriate management strategies can be framed for their improvement.

In view of the above, the study investigates public spaces in the context of three Indian cities and identifies the quality attributes/criteria based on a survey of users' opinion and observational studies of selected public spaces. Further, a framework for the evaluation of the quality of public spaces employing the Public Space Quality Index (PSQI), has been developed and applied in selected public spaces. Using the above methodology, public spaces in a city with different performance levels, and factors responsible for the same can be identified, which can then become the basis for formulating appropriate management strategies for their improvement and comparing performances of public spaces in specific areas of a city/different cities to encourage competitiveness among cities to improve the quality of their public realm.
\end{abstract}

Keywords: public spaces, quality, Indian cities, attributes, evaluation, management

To cite this article:

Praliya, S., Garg, P. (2019). Public space quality evaluation: prerequisite for public space management. The Journal of Public Space, 4(I), 93-126, DOI 10.3289I/jps.v4il .667

This article has been double blind peer reviewed and accepted for publication in The Journal of Public Space.

cc) (1) This work is licensed under a Creative Commons Attribution - Non Commercial 4.0 International License https://creativecommons.org/licenses/by-nc/4.0/ 


\section{Introduction}

Quality of life in a city and its image are often associated with its public spaces, as these not only provide relaxation from stress and help in reducing mental fatigue and aggressive behaviourin people (Cackowski and Nasar, 2003; Hartig et al., I99I; Kaplan, 200 I; Kuo and Sullivan, 200 la, b; Rossman and Ulehla, 1977; Ulrich 198I, 1984), but they are also hubs of activities and act as interaction nodes, resting areas, and children's play areas (Chiesura, 2004; Korpela et al., 200I). These open spaces also act as the lungs of cities, maintaining a certain level of biodiversity and providing niches for animals and birds. Public spaces also provide opportunities for cultural activities and preservation of heritage areas. The presence of these spaces in an area attracts business investments and tourism, hence supporting local economies (Beer et al. 2003; De Sousa 2003; Luttik, 2000; Morancho, 2003; Rodenburg et al., 200 I; Swanwick et al. 2003). Public open spaces contribute to quality of life (Madanipour, 1999). Thus, due to their role in improving liveability, environmental quality and sustainability, public spaces are essential for towns and cities in developed as well as developing nations. However, despite being such an important part of settlements, the state of public spaces in many cities, particularly in developing countries like India, is far from desirable both in terms of quantity as well as quality. There is a considerable difference between the norms/provision of public spaces, facilities and amenities provided, and their quality in cities in developed, rich countries and those found in developing, poor countries, more so in small and medium towns (Praliya, Pushplata, 2012; Praliya, Pushplata, 2016) and the areas inhabited by lower income groups. Though considerable research exists on the evaluation of successful public spaces in developed countries and their qualities, that are primarily aimed at providing better design solutions, this issue has not been addressed in countries like India where the context, as well as the patterns of usage of public spaces, are vastly different. Also, the studies done on public space management (Carmona, 2010), which are essential for ensuring quality public spaces, are more relevant to their specific contexts. Therefore, understanding the usage, factors/conditions responsible for the quality of public spaces and their evaluation in the context of Indian cities is essential, so that proper management strategies can be formulated for ensuring successful public spaces.

\section{Background}

The value of public spaces, criteria of successful public spaces, quality attributes and their evaluation, and management of public spaces have been recognised and researched on for some time now. Concerns for safety, diversity and the vitality of cities, particularly in the public realm were addressed by Jane Jacobs - the famous urban activist in $196 \mathrm{I}$ (Jacobs, 1992), and the issues of failure and/or success of public spaces have been addressed by William Whyte in The Social Life of Small Urban Spaces (1980), wherein in order to find out what attracts people most he highlighted the role of sitting spaces, comfort, presence of food, retailing, streets and the main space's relationship to pedestrian flow and external stimuli (W.H. Whyte, 1980). Though quantitative distribution of public spaces across towns and cities is based on norms and standards, these do not address the qualitative and management aspects of these spaces (TüzinBaycan-Leventand, Peter Nijkamp, 2008). Significant works identifying criteria relating to good quality and what constitutes successful spaces include works by Gehl, Carmona, Project for Public Spaces (a non-profitable organisation), Carr, Smith, Ewing \& Clemente, and Mehta. 
Jan Gehl (1987) developed I 2 quality criteria for good design of public open spaces, which were categorised under three main themes: protection, comfort and enjoyment. Whereas the first theme, protection, dealt with obligatory preconditions to staying outside and included criteria of protection against traffic and accidents, protection against harm by others and protection against unpleasant sensory experiences; the second theme, comfort, dealt with preconditions for spending more time in public space and included criteria of possibilities for walking, possibilities for standing and staying, possibilities for sitting, possibilities to see, possibilities for hearing and talking, and possibilities for play, and unfolding activities. The third theme, enjoyment, included criteria of possibilities for enjoying positive aspects of climate, aesthetic quality and positive sensory experience. Quality criteria developed by Matthew Carmona (2010) reflect the social, economic and environmental characteristics of public spaces, such as cleanliness, tidiness, accessibility, attractiveness, comfort, inclusiveness, vitality and viability, function, distinctiveness, safety and security, robustness, greenness, unpollutedness and capacity for fulfillment. Four key qualities/criteria for high quality environments in public spaces identified by Project for Public Spaces (2000) are access and linkage, uses and activities, comfort and image, and sociability.

The six main categories of community needs and quality criteria in public spaces developed by Smith et al. (1997) include liveability, character, connection, mobility, personal freedom and diversity. Carr et al. (1992) have identified people's needs in public spaces in terms of comfort, relaxation, passive engagement, active engagement, discovery and encounter with a place. Ewing\& Clemente (2013) mention five intangible qualities of urban design that are applied to streets as public spaces i.e. imageability, visual enclosure, human scale, transparency and complexity. Mehta (2013) identified the five dimensions of public spaces as being inclusiveness, meaningfulness, safety, comfort and pleasurability, for evaluating the quality of public spaces. Some other studies by Moudon 1989; Jacobs 1993; Fyfe 1998; Loukaitou-Sideris; and Ehrenfeucht 2009 have identified criteria related to the use of, nature and variety in public spaces.

Further, objective evaluation of the quality of public places has been considered necessary for providing better design solutions. These include a matrix with key words for urban design by Jan Gehl, which dates back to 1974, from which the twelve aforementioned criteria or rules for good design of public spaces were extracted. Carr et al (1992) proposed the assessment of the quality of outdoor spaces as being "poor" or "good", in terms of the occurrence of necessary outdoor activities, optional activities and resultant social activities. The Project for Public Spaces (PPS) developed The Place Diagram as a tool to assist people in judging any place, good or bad, against the four main criteria of access and linkage, uses and activities, comfort and image, and sociability as mentioned above. These four main criteria can be further judged according to a number of intuitive or qualitative aspects. The qualitative aspects for the evaluation of access and linkage include: convenience to use, visibility, easiness to get to and move within; whereas those relating to uses and activities include: providing a reason to be in a space, and vitality and uniqueness; for comfort and image these are: safety, cleanliness, greenness, being full of character and attractiveness; and for sociability the criteria include: fostering neighborliness, friendship, interaction, diversity and pride. These qualitative aspects can be further measured by quantitative parameters. Specific questions to be considered for each of the criteria have also been suggested. Whereas, Vikas Mehta (2007) has provided a theoretical framework to evaluate quality in public spaces across five dimensions of 
public space i.e. inclusiveness, meaningfulness, safety, comfort and pleasurability using the Public Spaces Index (PSI) constructed of 42 to 45 variables. Due to its objective, rational approach and ease of understanding/interpretation by stakeholders, a similar framework for evaluation has been adopted for this study.

Lately, the significance of proper management for ensuring the quality and success of public spaces has also begun to be recognised. Appropriately managed public spaces not only add to the image and identity of towns and cities, but also add to the competitiveness of towns and cities (Emmanuel 1997; Iverson and Cook 2000; Jim 2004; Keil 2003; Robbins et al. 200I; Swyngedouw and Heynen 2003; Taylor et al. 1998). Proper management of spaces improves the living, working, rejuvenating, recreational and tourism experiences and add to the overall quality of life, as mentioned by him 'if public spaces are poorly managed, they not only lead to the deterioration of the public realm as a whole but they also reduce the attractiveness of a city's overall image'(Madanipour, 1999). Matthew Carmona and Claudio De Magalhaes (2006) have identified major barriers resulting in a decline in quality in public open spaces, which they identified as "loopholes in regulations for the uses and conflicts between uses; inappropriate maintenance routine; lack of investments into and on-going resourcing of public space; lack of coordination between activities and stakeholders and other interventions." (Carmona, 20I0) has also identified three models of public space management in the context of England.

However, in view of the considerable differences between the socio-economic administrative - political context of developing countries, particularly of small and medium towns, strategies for managing public spaces are likely to be different because not only the norms/provision of public spaces and facilities and amenities (to be) provided are different; users' socio-economic status, the attitude of the general public, the usage and maintenance of public spaces, the financial status and the organisational structure of the authorities responsible for their maintenance, and the enforcement of law and order are significantly different than the context where research on public space management has been done. Therefore, it is necessary to understand the problems and issues in public spaces, the criteria for ensuring quality public spaces, and develop an evaluation framework to find solutions in differing contexts. Accordingly, the present study investigates the attributes and criteria pertaining to quality in public spaces in the context of three Indian cities which represent large, medium and small cities respectively and develops a framework for evaluating the quality of public spaces, which can assist in identifying public spaces of different quality, as well as, formulating strategies for their improvement.

\section{Method}

The study consists of three parts. In the first part, an extensive literature review was carried outto understand the essential aspects of public spaces and identify the quality criteria in successful public spaces. In the second part, selected public spaces in the context of three Indian cities, namely Delhi, Dehradun and Roorkee representing large, medium and small city respectively, have been studied in detail; which included on-site observations of the surroundings of the spaces, uses/activities taking place, present condition, and existing infrastructure facilities and amenities.

Discussions were also held with various stakeholders to find out about users' needs and expectations and to understand the maintenance and management aspects, such as: 
operational hours, authorities responsible for management, type and number of personnel employed, and expenditure incurred. Together, these led to an identification of the problems and issues present in each context and thereafter to the identification of criteria/aspects specific to the context of these cities, including management parametersthe presence or absence of which were considered as being responsible for the success or failure of the spaces. The 49 parameters thus identified, named quality attributes, were categorised into 8 categories collectively Dimensions of Quality (Table I). These eight dimensions of quality are entitled; Accessibility and Linkage, Maintenance, Attractiveness and Appeal, Comfort, Inclusiveness, Activities and Uses, Purposefulness, and Safety and Security. Whereas, the accessibility and linkage dimension is associated with different means of physical access and visual approaches, as well connectivity to nearby and far-off areas of the city through different modes; maintenance is associated with the attributes that help in preserving the state of parks such that the space is able to perform the function/uses it is meant to. The attractiveness and appeal dimension is associated with the possession of qualities or features that make the space appealing to the senses; whereas comfort is the state of being at ease due to certain features, elements and climatic conditions present in the space and; inclusiveness refers to the characteristics of a space which makes it usable by all, irrespective of different physical, social and economic parameters or external influences. The activities and uses dimension refers to different activities taking place in a space and the uses a space is put to; whereas purposefulness is associated with accommodating the needs of different users, which change with time - justifying its planning, design and the uses it is put to.The safety and security dimension is associated with a feeling of being protected and free from; any kind of threat: physical, mental or emotional; the presence or absence of certain undesirable elements or behaviours, and/or; certain conditions like broken play equipment/furniture which can cause injury/be harmful.

In the third part,the PSQI was developed to evaluate these dimensions of quality by averaging the feedback received from a survey which consisted of users' opinions: assigning weightages and calculating the overall performance scores of different spaces selected for study, as explained in detail below.

\section{I Public Space Quality Index (PSQI)}

Employing the PSQI for evaluating the performance of public spaces includes; calculating an average rating for each of the quality attributes $\left(R_{d}\right)$; assigning weightages to quality attributes $(W d)$; calculating the Attribute Score $\left(S_{d}\right)$; Dimension Score $\left(D_{i}\right)$ and; the overall Performance Score of a public space $\left(P_{p}\right)$, as explained in detail below.

\subsection{Assigning Weightages to Attributes}

Assigning weightages is crucial part of the evaluation of the quality of public spaces and depends on the way in which a public space is expected to perform in any particular dimension (aspect) from the users' perspectives. 
Public space quality evaluation

Table I. Public space quality index highlighting dimensions of quality and their attributes

\begin{tabular}{|c|c|c|c|c|c|c|c|}
\hline $\begin{array}{l}\text { I. Accessible \& } \\
\text { Linked }\end{array}$ & 2. Maintenance & $\begin{array}{l}\text { 3. Attractiveness } \\
\text { and appeal }\end{array}$ & 4. Comfort & 5.Inclusiveness & $\begin{array}{l}\text { 6. Activity and } \\
\text { uses }\end{array}$ & $\begin{array}{l}7 . \\
\text { Purposefulness }\end{array}$ & 8. Safety and security \\
\hline $\begin{array}{l}\text { Visibility of space } \\
\text { from a distance }\end{array}$ & $\begin{array}{l}\text { Management of } \\
\text { litter and filth }\end{array}$ & Aesthetic appeal & $\begin{array}{l}\text { Comfortable sitting } \\
\text { areas }\end{array}$ & $\begin{array}{l}\text { Used by all, irrespective } \\
\text { of age, race, class, gender } \\
\text { and physical abilities }\end{array}$ & Walking & $\begin{array}{l}\text { Suitability of layout } \\
\text { and design }\end{array}$ & $\begin{array}{l}\text { Presence of adequate } \\
\text { lighting, illumination }\end{array}$ \\
\hline $\begin{array}{l}\text { Visibility of space } \\
\text { from immediate } \\
\text { surroundings }\end{array}$ & $\begin{array}{l}\text { Presence and } \\
\text { condition of waste } \\
\text { bins }\end{array}$ & $\begin{array}{l}\text { Visual pleasure in the } \\
\text { overall space }\end{array}$ & $\begin{array}{l}\text { Presence and } \\
\text { condition of public } \\
\text { facilities and } \\
\text { amenities }\end{array}$ & $\begin{array}{l}\text { Control of entrance to } \\
\text { the space according to } \\
\text { specified timings }\end{array}$ & Socialising & Ambience & Surveillance measures \\
\hline Accessibility walking & $\begin{array}{l}\text { Condition of } \\
\text { green areas }\end{array}$ & $\begin{array}{l}\text { Uncluttered view of } \\
\text { the space }\end{array}$ & $\begin{array}{l}\text { Presence and } \\
\text { condition of shelter } \\
\text { spaces }\end{array}$ & $\begin{array}{l}\text { Control of entrance by } \\
\text { entrance fee }\end{array}$ & $\begin{array}{l}\text { Physical fitness- } \\
\text { related activity }\end{array}$ & & Security arrangements \\
\hline $\begin{array}{l}\text { Accessibility via } \\
\text { private transport }\end{array}$ & $\begin{array}{l}\text { Condition of park } \\
\text { iinfrastructure }\end{array}$ & $\begin{array}{l}\text { Presence, quality and } \\
\text { condition of public art }\end{array}$ & $\begin{array}{l}\text { Presence of } \\
\text { Signage's }\end{array}$ & & Children's play & & $\begin{array}{l}\text { Check on entry of } \\
\text { animals }\end{array}$ \\
\hline $\begin{array}{l}\text { Accessibility via public } \\
\text { transport }\end{array}$ & $\begin{array}{l}\text { Conditionsfor } \\
\text { walking, jogging, } \\
\text { cycling tracks }\end{array}$ & $\begin{array}{l}\text { Arrangement of park } \\
\text { furniture }\end{array}$ & $\begin{array}{l}\text { Provision of parking } \\
\text { spaces }\end{array}$ & & Sports and games & & $\begin{array}{l}\text { Check on criminal } \\
\text { activities }\end{array}$ \\
\hline \multirow[t]{5}{*}{$\begin{array}{l}\text { Ease of movement in } \\
\text { and around }\end{array}$} & $\begin{array}{l}\text { Management of } \\
\text { graffiti, vandalism }\end{array}$ & Landscape & $\begin{array}{l}\text { Provision of buffer } \\
\text { from traffic nuisance }\end{array}$ & & Family outings & & $\begin{array}{l}\text { Check on antisocial } \\
\text { elements }\end{array}$ \\
\hline & & $\begin{array}{l}\text { Condition of } \\
\text { grass/verges }\end{array}$ & & & $\begin{array}{l}\text { Contact with flora } \\
\text { and fauna }\end{array}$ & & $\begin{array}{l}\text { Availability of } \\
\text { information/ complaint } \\
\text { center }\end{array}$ \\
\hline & & $\begin{array}{l}\text { Presence and } \\
\text { condition of flowered } \\
\text { areas }\end{array}$ & & & Educational visits & & \\
\hline & & $\begin{array}{l}\text { Presence of themed } \\
\text { play area }\end{array}$ & & & $\begin{array}{l}\text { Events and } \\
\text { gatherings }\end{array}$ & & \\
\hline & & & & & Relaxing & & \\
\hline
\end{tabular}

98 | The Journal of Public Space, 4(I), 2019 | ISSN 2206-9658

City Space Architecture / UN-Habitat 
A survey was conducted to obtain the users' opinions on a scale of I to 5 for each attribute, so as to understand the comparative significance of the attributes associated with different dimensions in the context of Indian cities; accordingly, ratings were assigned to the 49 attributes of the qualities identified earlier. A total of 163 people were surveyed for this purpose. Assigning weightages on the same scale for each dimension facilitates a proper evaluation, as each dimension can be given the same weightage of 10 . Therefore, the rating of each attribute was converted into weightages by calculating the relative importance of each attribute, where the total of all the attributes for a specific dimension adds up to a total of 10 .

\subsection{Evaluating Performance of Public Spaces Using the PSQI}

A complete performance of a public space can be obtained by application of the PSQI, taking users' opinions on different attributes into account. The application of the PSQI for "Park P" is presented in Table 2, for the accessible and linked dimension. An average rating (Rd) by users, for each of the attributes is calculated, which in this case is $R_{1}, R_{2}$, $R_{3}, R_{4}, R_{5}$ and $R_{6}$ for respective attribute of the selected dimension.

Average Rating for respective attributes $\left(R_{d}\right)=\left\{\left[U_{1}+U_{2}+\ldots . U_{n}\right] / n\right\}$

where,

$\mathrm{n}$ - is the total number of surveys conducted to gather users' opinions

$R_{d}$ - average rating

$U_{n}$ - individual ratings for respective attributes

The average rating for each attribute is then multiplied by the weightages $\left(W_{d}\right)$ of the respective attributes to calculate respective attribute scores $\left(S_{d}\right)$ which in this case are $\mathrm{S}_{1}, \mathrm{~S}_{2}, \mathrm{~S}_{3}, \mathrm{~S}_{4}, \mathrm{~S}_{5}$ and $\mathrm{S}_{6}$ - as shown in Table 2.These attribute scores present the performance of public space on the basis of each of the attributes.

Attribute Score $\left(S_{d}\right)=W_{d} \times R_{d}$

where,

$\mathrm{d}-$ is the total number of attributes

$R_{d}$ - average rating for respective attributes

$W_{d}$ - Weightages for respective attributes

The attribute scores for respective dimensions are then added up to get an overall performance score of a public space for any particular dimension, which in this case is accessible and linked having a dimension score $D_{1}$ as seen in Table 2 .

Dimensions Score for each of the dimensions $(\mathrm{Di})=\mathrm{S}_{1}+\mathrm{S}_{2}+\ldots . \mathrm{S}_{\mathrm{d}}$ where,

$\mathrm{i}$ - is the total number of dimensions

$\mathrm{S}_{\mathrm{d}}$ - Attribute scores

In a similar way the scores for all the dimensions are calculated which are $D_{1}, D_{2}, D_{3}$, $D_{4}, D_{5}, D_{6}, D_{7}$ and $D_{8}$ - as shown in Table 2 . Since the maximum rating for an attribute can be 5 (on the I to 5 scale used in the survey) the maximum score that can be achieved for any dimension will be 50 . For ease of understanding, the Dimension Score is converted into a percentage.

The overall performance score, indicating the quality of a public space is calculated by adding up the total scores achieved for each dimension, which totals up to be a maximum of 400 . 
Public space quality evaluation

Overall Performance of Park $\left(P_{p}\right)=\left[\left(D_{1}+D_{2}+\ldots . D_{i}\right) / i\right]$

where, $D_{i}=$ Dimension Score for each of the dimensions

The PSQI can be applied to all the parks taken up for study and the overall performance of the parks can be measured. The PSQI is further used to evaluate the performance of selected studies in the next section, and helps in bringing out the comparative picture of the studies taken up. The method adopted provides an easy and clear understanding of the overall performance of a public space.

Table 2: Application of PSQI

Performance evaluation on Eight Dimensions of Quality using PSQI

\begin{tabular}{|c|c|c|c|c|c|c|}
\hline \multirow[b]{2}{*}{$\begin{array}{l}\text { Dimensions } \\
\text { of Quality }\end{array}$} & \multirow[b]{2}{*}{$\begin{array}{l}\text { Attributes } \\
\text { for } \\
\text { Dimension }\end{array}$} & \multirow[b]{2}{*}{$\begin{array}{l}\text { Weightage } \\
\left(W_{d}\right)\end{array}$} & \multicolumn{4}{|l|}{ Swarnajayanti Park } \\
\hline & & & $\begin{array}{l}\text { Average Rating by } \\
\text { users }\left\{R d=\left[U_{1}+\right.\right. \\
\left.\left.U_{2}+\ldots U_{n}\right] / n\right\}\end{array}$ & $\begin{array}{l}\text { Attribute } \\
\text { Score }( \\
S_{d}=W_{d} x \\
\left.R_{d}\right)\end{array}$ & $\begin{array}{l}\text { Dimension Score }[\mathrm{Di} \\
\left.=\mathrm{S}_{1}+\mathrm{S}_{2}+\ldots \mathrm{S}_{\mathrm{d}}\right]\end{array}$ & $\begin{array}{l}\text { Dimension } \\
\text { score out of } \\
100\end{array}$ \\
\hline \multirow{6}{*}{$\begin{array}{l}\text { Accessible } \\
\text { and Linked } \\
\left(D_{1}\right)\end{array}$} & $\begin{array}{l}\text { Visibility } \\
\text { from far } \\
\text { away }\end{array}$ & $W_{1}$ & $\mathrm{R}_{1}$ & $\mathrm{~S}_{1}$ & \multirow{6}{*}{$\begin{array}{l}S_{1}+S_{2}+S_{3}+S_{4}+S_{5}+S_{6}= \\
D_{1}\end{array}$} & \multirow{6}{*}{$\begin{array}{l}\mathrm{D} \mid * 100 / 50 \\
=\mathrm{PD}_{1} \%\end{array}$} \\
\hline & $\begin{array}{l}\text { Visibility } \\
\text { from nearby }\end{array}$ & $W_{2}$ & $\mathrm{R}_{2}$ & $\mathrm{~S}_{2}$ & & \\
\hline & $\begin{array}{l}\text { Accessibility } \\
\text { on foot }\end{array}$ & $W_{3}$ & $\mathrm{R}_{3}$ & $\mathrm{~S}_{3}$ & & \\
\hline & $\begin{array}{l}\text { Accessibility } \\
\text { by private } \\
\text { vehicle }\end{array}$ & $\mathrm{W}_{4}$ & $\mathrm{R}_{4}$ & $\mathrm{~S}_{4}$ & & \\
\hline & $\begin{array}{l}\text { Accessibility } \\
\text { by public } \\
\text { transport }\end{array}$ & $W_{5}$ & $\mathrm{R}_{5}$ & $\mathrm{~S}_{5}$ & & \\
\hline & $\begin{array}{l}\text { Ease of } \\
\text { movement }\end{array}$ & $W_{6}$ & $\mathrm{R}_{6}$ & $\mathrm{~S}_{6}$ & & \\
\hline \multicolumn{3}{|c|}{ Maintenance $D_{1}$} & & & & $\mathrm{PD}_{1} \%$ \\
\hline \multicolumn{3}{|c|}{ Attractiveness and Appeal $D_{2}$} & & & & $\mathrm{PD}_{2} \%$ \\
\hline \multicolumn{3}{|l|}{ Comfort $\mathrm{D}_{3}$} & & & & $\mathrm{PD}_{3} \%$ \\
\hline \multicolumn{3}{|c|}{ Inclusiveness $\mathrm{D}_{4}$} & & & & $\mathrm{PD}_{4} \%$ \\
\hline \multicolumn{3}{|c|}{ Activities and uses $D_{5}$} & & & & $\mathrm{PD}_{5} \%$ \\
\hline \multicolumn{3}{|c|}{ Purposefulness $D_{6}$} & & & & $\mathrm{PD}_{6} \%$ \\
\hline \multicolumn{3}{|c|}{ Safety and Security $D_{7}$} & & & & $\mathrm{PD}_{7} \%$ \\
\hline \multicolumn{3}{|c|}{ Overall performance of park $\left[P p=\left(D_{1}+D_{2}+\right.\right.$} & $\left.\left.\ldots . D_{i}\right) / i\right]$ & & & $P_{D}$ \\
\hline
\end{tabular}

100 | The Journal of Public Space, 4(I), 2019| ISSN 2206-9658

City Space Architecture / UN-Habitat 


\begin{tabular}{ll}
\hline $\begin{array}{l}\mathrm{d} \text { - is the total number of attributes, which vary for each } \\
\text { dimension }\end{array}$ & $\begin{array}{l}W_{d} \text {-Weightages for respective } \\
\text { attributes }\end{array}$ \\
$\begin{array}{l}\mathrm{n} \text { - is the total number of surveys conducted to gather users' } \\
\text { opinions }\end{array}$ & $\begin{array}{l}R_{d} \text { - average rating for respective } \\
\text { attributes }\end{array}$ \\
$\mathrm{i}$ - is the total number of dimensions & $\begin{array}{l}U_{n} \text { - individual ratings for respective attributes } \\
S_{d}-\text { Attribute scores }\end{array}$ \\
$D_{i}-$ Score for each of the dimensions & $\begin{array}{l}P D_{i}-\text { is \% of park performance in } \\
\text { each dimension }\end{array}$
\end{tabular}

\section{Evaluating Public Spaces in Indian Cities using the PSQI}

Selected public spaces from three different cities in India are evaluated according to eight Dimensions of Quality to assess the performance of each area using the PSQI. Performance evaluations for all the selected public spaces in each of the city are carried out and compared. This facilitates understanding regarding the performance of parks individually and the performance of parks in different cities; highlighting the differences and similarities between the scenarios of parks in big, medium and small cities. The studies of all the selected public spaces are discussed in the sections ahead. However, since public spaces in Indian cities vary in typology, quality, context, use and their management process, and one type of public space available in one city might not be available in another city (as many of these spaces are peculiar and specific to that context) and parks are the most common and preferred public in cities, park as a typology of public space has been taken up for study.

\section{I Study Area: Case of Three Citie}

Studies are taken up from three different cities: Delhi, Dehradun and Roorkee representing the scenario of big cities, medium-sized cities and small-sized cities in India respectively. Further, as park is the only typology of public spaces taken up for study; the parks are chosen in such a way that they offer a broad picture about the typology and sizes of parks existing in Indian cities.

\subsection{Selected Studies in Delhi}

A total of five parks managed by three different public bodies are taken up as studies:

- Sawarn Jyanti Park and Mahavir Park, managed by the Delhi Development Authority(DDA);

- Central Park and Children Park, managed by the New Delhi Municipal Corporation (NDMC);

- Parshuram Park, managed by the Municipal Corporation of Delhi (MCD).

\subsection{Sawarn Jyanti Park}

Swarna Jyanti Park is a prestigious, verdant landmark in North Delhi, located in Sector10 of Rohini, a well-developed residential city in North West Delhi, India. It was one of the DDA's first sub-city projects, beginning in the 1980s it's aim was to provide a composite society for all income groups. As it is a planned area, the distribution of parks and other facilities are based on development norms. Swarna Jyanti Park is part of 
the planned development which was opened for use in 2002. Continuous phase wise developments are still carried out to date, along with regular maintenance, management and redevelopments. Large central green areas, new entrance plazas, parking spaces, open gyms, new swings, signage and direction boards are the major new additions to the park. The district park is abutted by two district centres known as the Twin District Centres to the south-west and north-east as shown in Fig. I. District Centre - I is currently under construction but already featuressome facilities such as 5 star hotels, branded shopping outlets and shopping malls; whereas District Centre - II is currently empty and is used as a site for political and religious gatherings as well as private functions. An Amusement Park is also planned adjacent to the park's boundary at the south-west corner. A 500 bed Ambedkar Hospital and Medical College, and the Rajiv Gandhi Cancer Research Institute and Hospital are also in the park's vicinity.

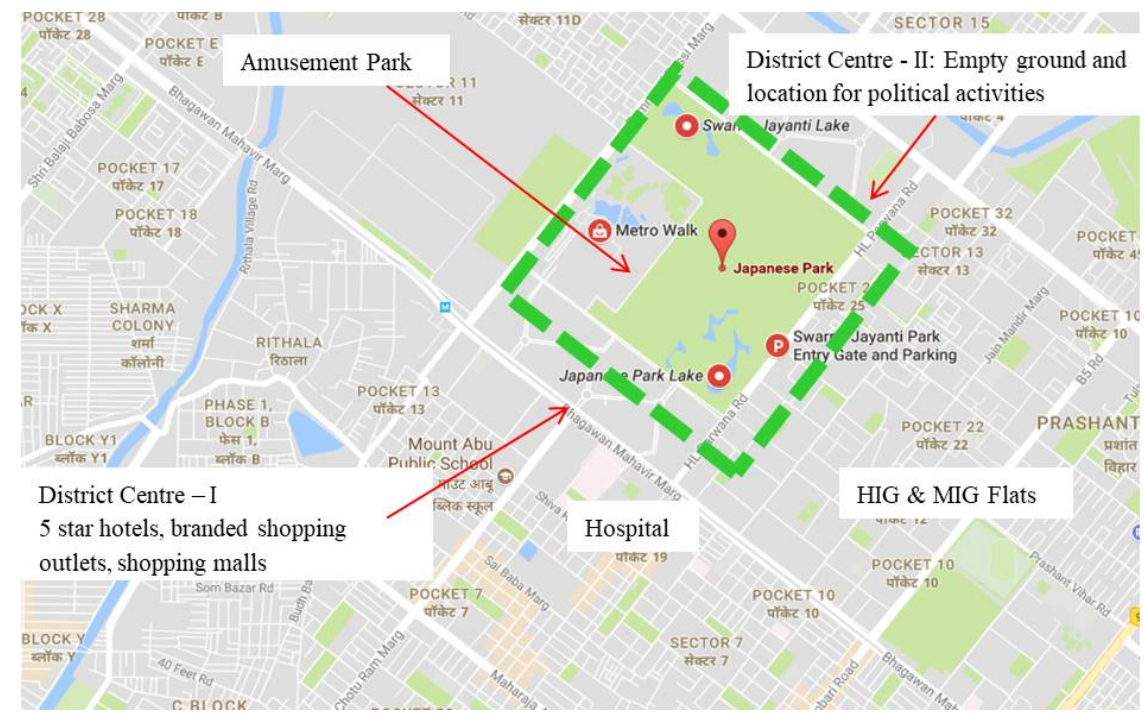

Figure I. Surroundings of Swarna Jyanti Park (source: Google).

The park is accessible from 5 a.m. until 8 p.m. for users from planned residential areas in the vicinity, throughout the summer and winter months. The park boasts good connectivity to the wider urban surroundings via metro, bus, rickshaw, car and on foot; this attracts crowds of users from other nearby areas and indeed from the entire city. The park has an average footfall of I5,000 people per day on weekdays and around 25,000 on weekends, and the figure can reach 40,000 during summer/winter vacations. The recorded footfall numbers reach over 100,000 on national holidays and during events. The park attracts visitors from different sections of society, despite being in the immediate vicinity of high income group (HIG) and middle income group (MIG) flats. Besides being a venue for resting, relaxation, bird feeding, fish/duck feeding and watching, a walking space and a children's play area, the park is also host to several other events where crowds from the entire city gather to participate. Several painting competitions, the Annual Flower Show, yoga and from time to time, meditation camps, keep the park vigorous and in the limelight. Hence, visitors from different age groups and genders are seen getting involved in different group or individual activities as shown in Figure 2. The park is renowned city-wide, attracting the attention of the authorities which results in its being better maintained and managed. 

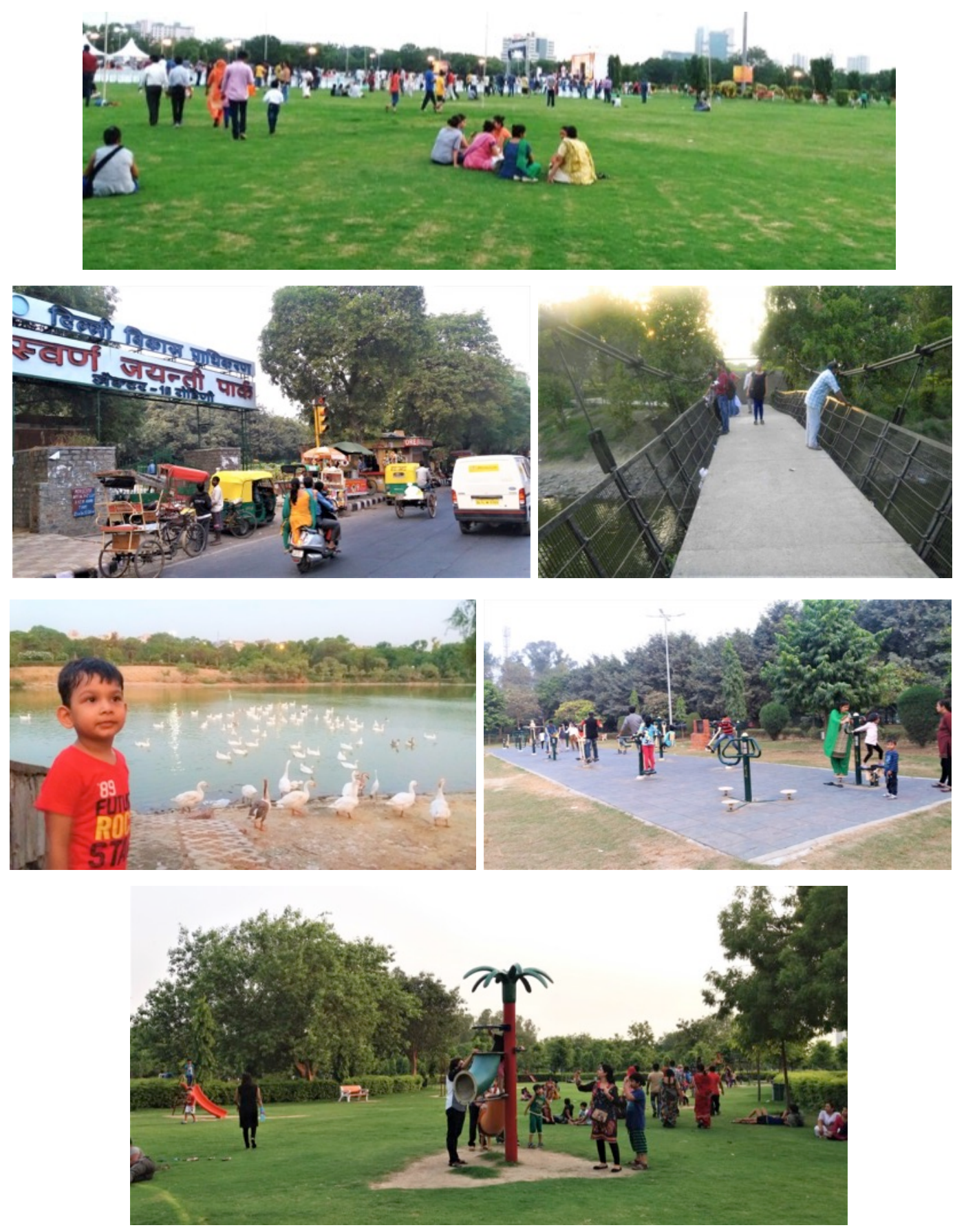

Figure 2. Features and activities in Swarna Jyanti Park.

\subsubsection{Mahavir Park}

Mahavir Park, also known as Vardhaman Vatika, has an area of 3.3 acres and is a planned park in a dense neighbourhood in pocket $\mathrm{H}$ 32, Sector 3, Rohini. Planned markets, a local Shiv Shakti Temple, Royal Pepper Banquet Hall and some shops are located in the vicinity and share their boundary along the north edge with Shwetambar Jain Sthanak and Decent Public School (Fig. 3). The park is a facility planned in accordance with 
development norms, but the park has undergone different phases of development from its being a green facility with boundaries to a park: well equipped with swings, an open gym, play areas and walking trails. The park has separate play area for children and adolescents and a small open-air gym has recently been provided to encourage users to stay active and fit (Fig. 4 and 5). In addition, a garbage dumping area has been provided at the west corner of the park. The park is a gathering spot for people from surrounding neighbourhoods, a place where they can take a break from their daily chores and monotony and access a much needed space to socialising, reap health benefits, and engage in multiple activities such as sitting around and socializing, taking a walk in the fresh air, doing yoga and doing physical exercise. The park has an average footfall of around 400 people per day on weekdays and weekends and is accessible to users without any time restrictions. Most of the users of the park are from lower and middle income groups from the neighbouring residential areas in pockets $\mathrm{H} 32, \mathrm{H} 34$, and D 16.

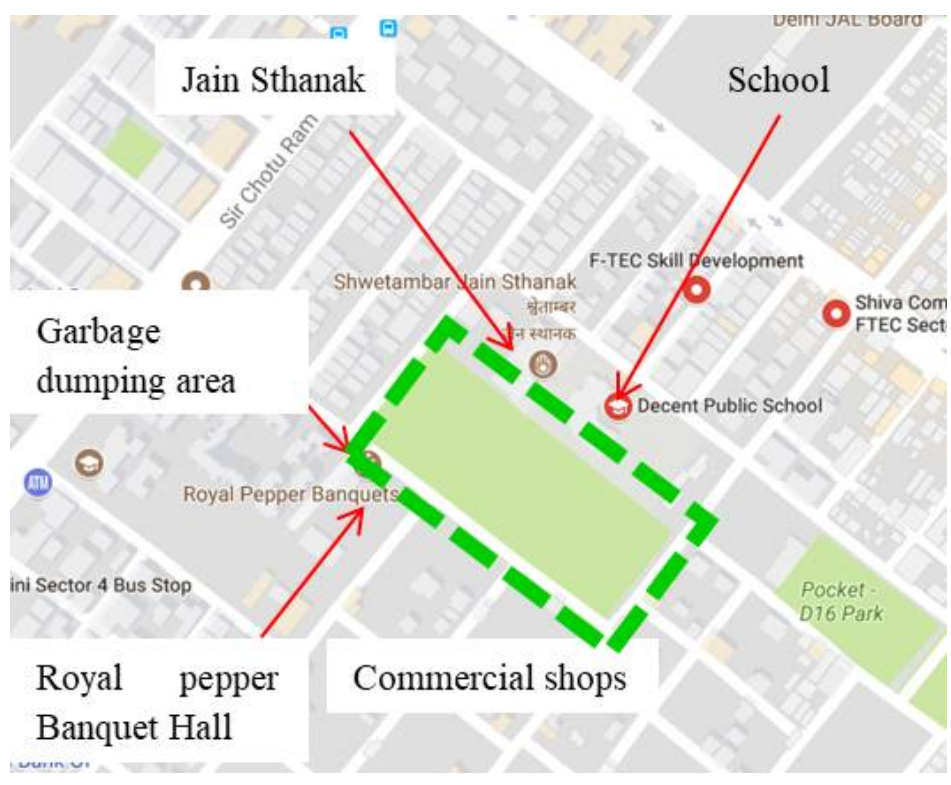

Figure 3. Location of Mahavir Park (Source: Google).
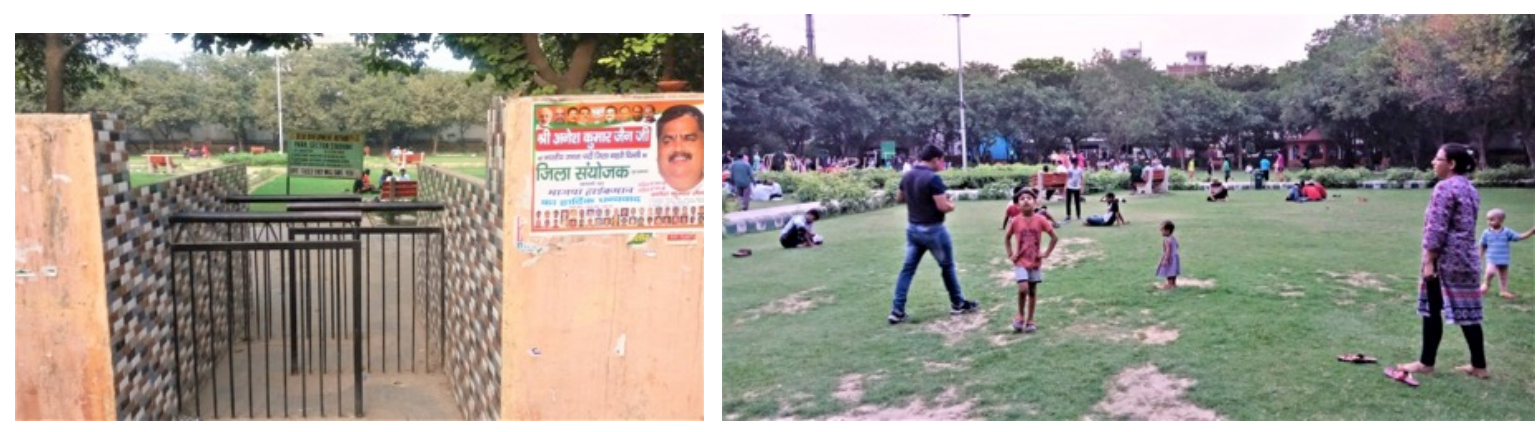

Figure 4. Entrance and main park area of Mahavir Park. 

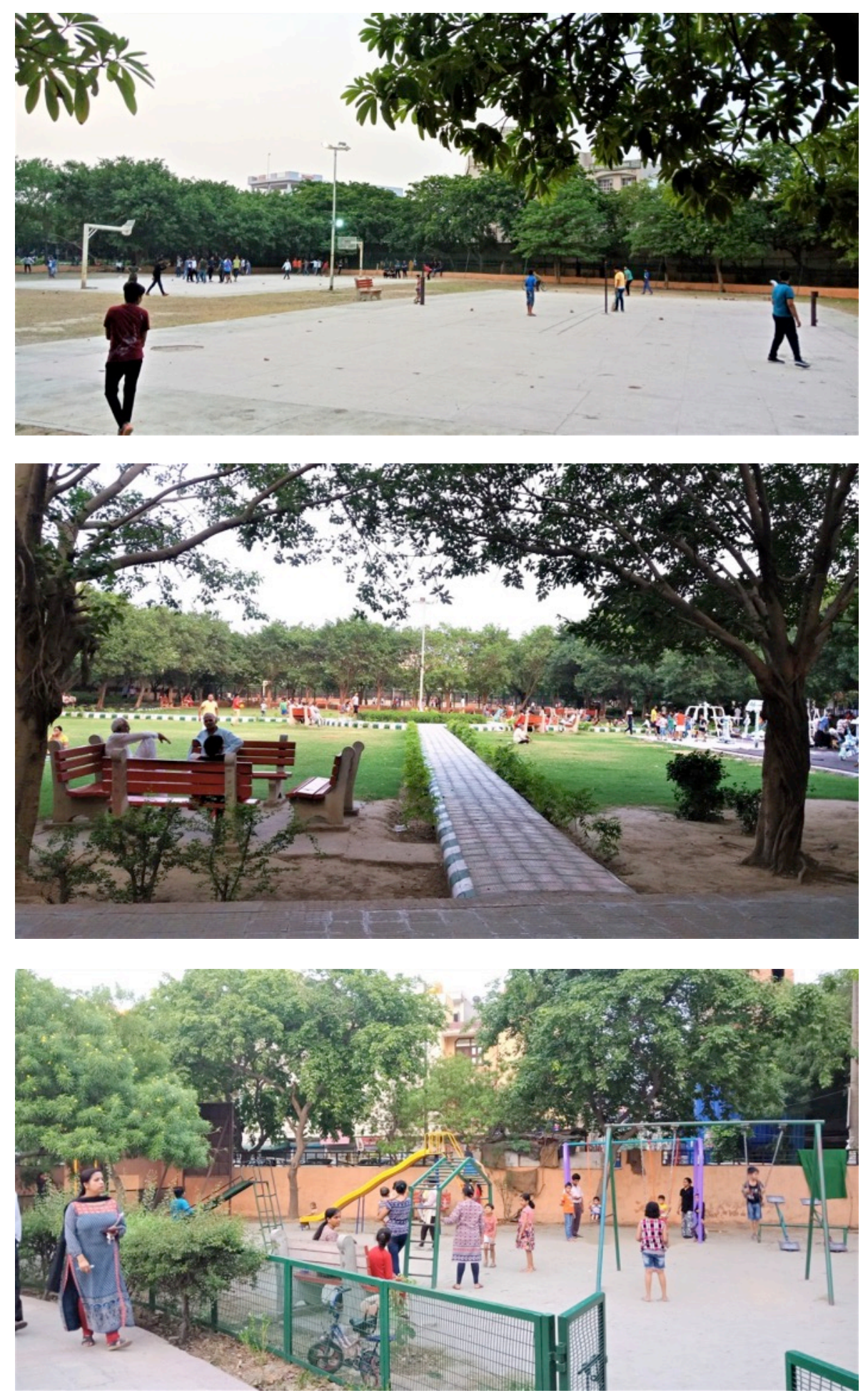

Figure 5. Features and activities in Mahavir Park. 


\subsubsection{Parshuram Park}

Bhagwan Parshuram Park is a 2.5 acre planned park in the dense neighbourhood of D 6, Sector 6, Rohini. The park is surrounded by DDA markets on two sides, to the northwest and south-east. The DDA market to the south-east mainly features service or repair shops. Whereas the market on the north-west side mainly features chemists, ATMs, Mother Dairy milk booths and temporary vegetable and fruit vendors. The Delhi Jal Board Zonal revenue office lies towards the south-west edge of the park. Pocket $D$ 7, 32 sq. m. of plotted residential quarters are provided towards the west side of the park, which have now been converted into commercial areas along the $30 \mathrm{~m}$ road lying along the north-west side of the park. A hanuman temple has also been built on the south-east side of the park, which attracts even more people (Fig. 6).

The park acts as breathing lungs for the area and is used by people from the surrounding areas who are mostly from lower and middle income groups; it provides people with an opportunity to take a break from their monotonous daily routine and it also serves as a resting space for daily-wage workers, household help, rickshaw pullers and vendors (Fig. 7). The park is also used for socialising. In addition, a weekly market is held along the $30 \mathrm{~m}$ road on the north-west side of the park, transforming the park into a thoroughfare. This is a neighbourhood park, so visiting the space is a part of local people's regular routine providing the park with an average footfall of about 250 people a day on weekdays, as well as on weekends. Part of the park is intentionally separated from the main park area by two narrow entrances and a low, grilled wall; however, this part of the park is mostly used by children to play cricket or other sports. The park is also used as a space for other events such as wedding functions, religious activities like Ram Lila and Dussehra celebrations. However, due to lack of cleaning, the aforementioned activities leave the space in a state of filth and disarray.

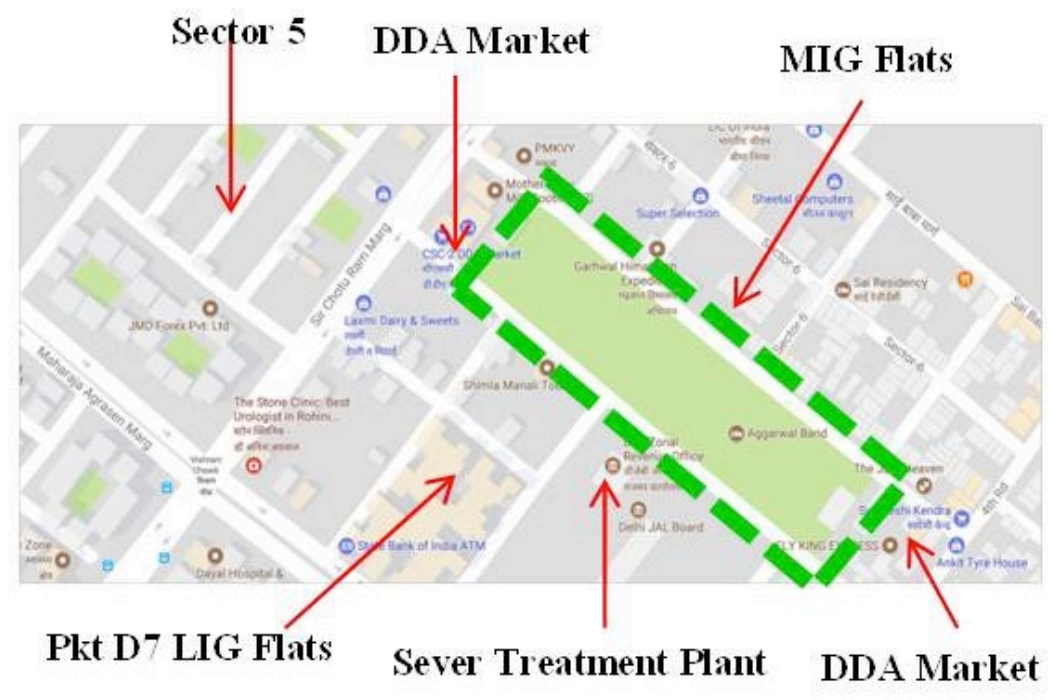

Figure 6. Location of Parshuram Park (Source: Google). 

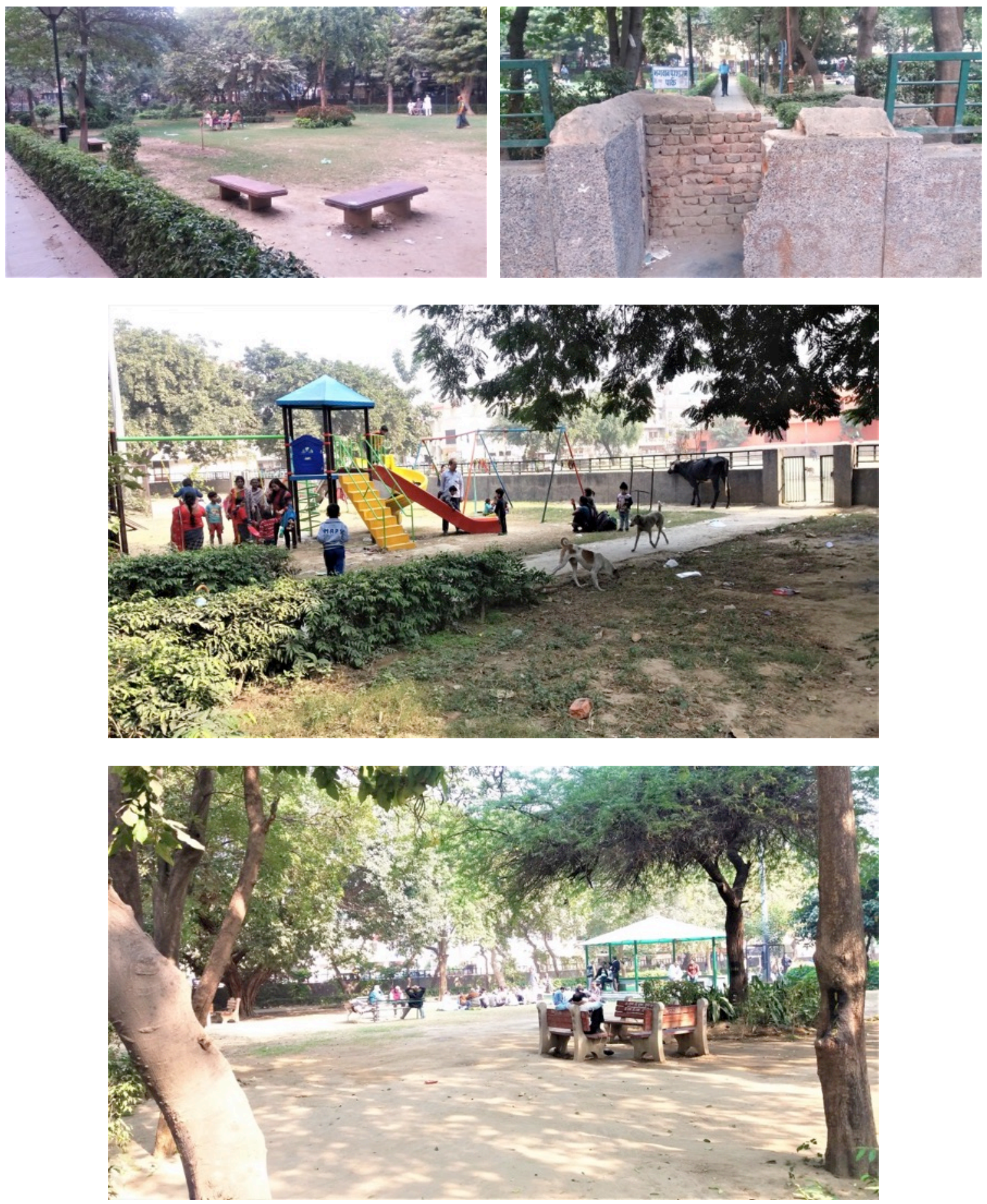

Figure 7. Images showing the features and activities in Parshuram Park.

The Park also has a small nursery and office where all the tools required for its daily maintenance are kept; despite this, the park is not a well maintained space. With time, new additions to the park have been made such as new swings, an open air gym and a large canopy in the central area to provide shelter in adverse weather conditions. But 
other than these, no significant improvements have been made to improve quality of the park.

\subsubsection{Central Park}

Central Park boasts an area of 10.25 acres and is located in the inner circle of Connaught Place in central Delhi. It is surrounded by Connaught Place's commercial areas - the largest financial, commercial and business center in Delhi - a very popular shopping area with several markets such as; the underground Palika Bazaar; the Janpath market and several branded outlets; a large number of good restaurants/good eating joints; entertainment destinations such as cinemas and multiplexes; a large number of offices; and a popular tourist area (Fig. 8). Furthermore, a large underground parking area, ATMs, and public toilets are provided in the immediate surroundings. The use of Central Park was discontinued in 2000 to make way for the construction of an underground metro station with six exits which was opened to public in 2005 and which provides access to different parts of Connaught Place.

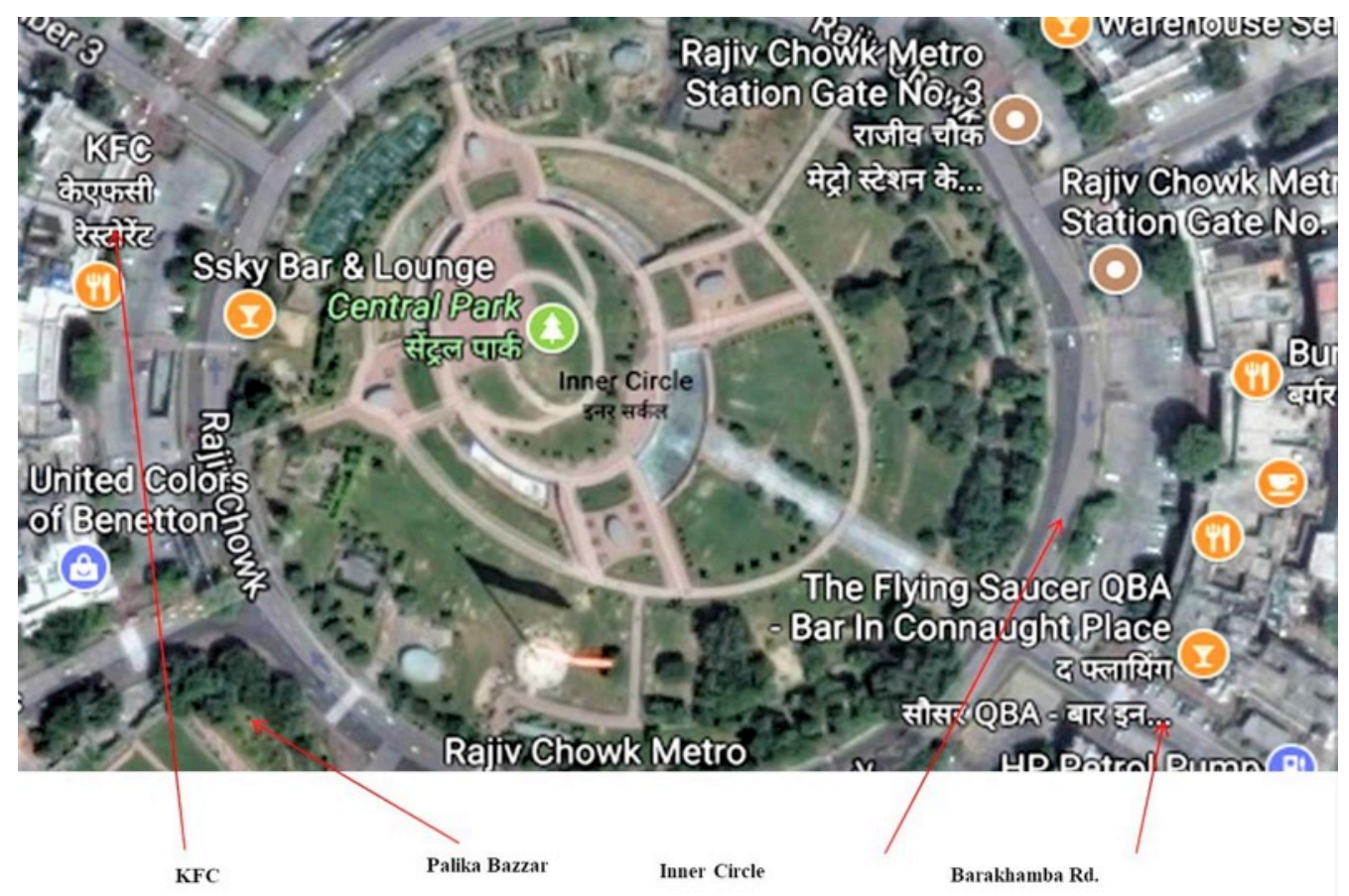

Figure 8. Location of Central Park, Connaught Place, Delhi (Source: Google).

The park now has 9 entrances and exits, of which two lead directly to the Rajiv Chowk metro station. It also has a beautiful lawn area, amphitheatre, water bodies, fountains and a water cascade. The national flag hoisted in the park is a special attraction, as it is the largest flag hoisted in India. Due to its location the park is used extensively and is a vibrant place with a pleasant ambience; people come to the park for relaxation, socialising and to take part in events such as different shows and New Year celebrations (Fig. 9). 

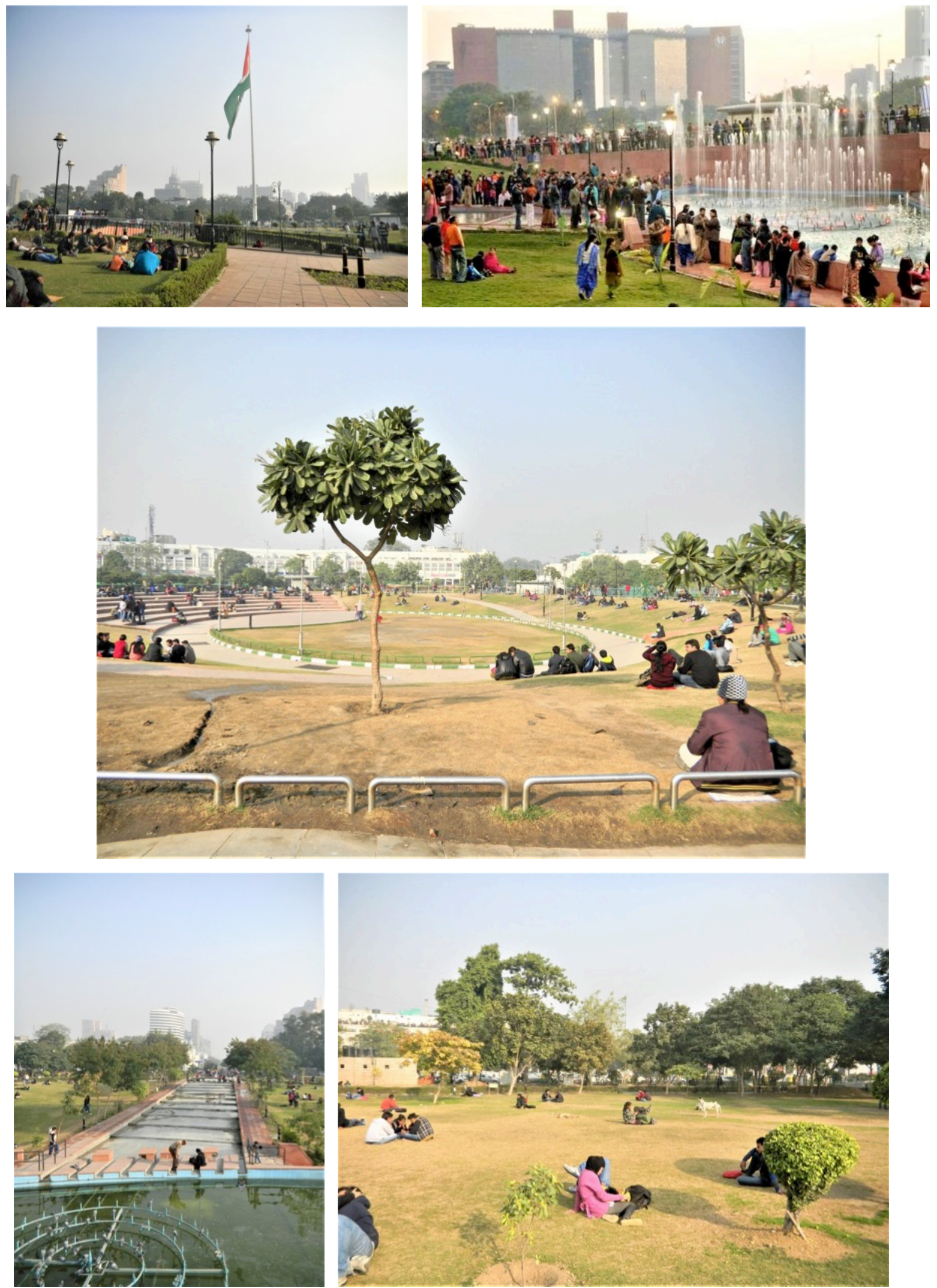

Figure 9. Features and activities in Central Park. 


\subsubsection{Children Park}

Children Park covers an area of 15 acres and is a one of a kind park provided in the India Gate area in central Delhi, it is part of the Central Vista of Lutyen's plan for NewDelhi. Surroundings of the park include: the India Gate, the National Gallery of Modern Art, the National Stadium, Hyderabad House and the War Memorial located around the C Hexagon, and the residential area popularly known as the Bungalow area (Fig. 10).

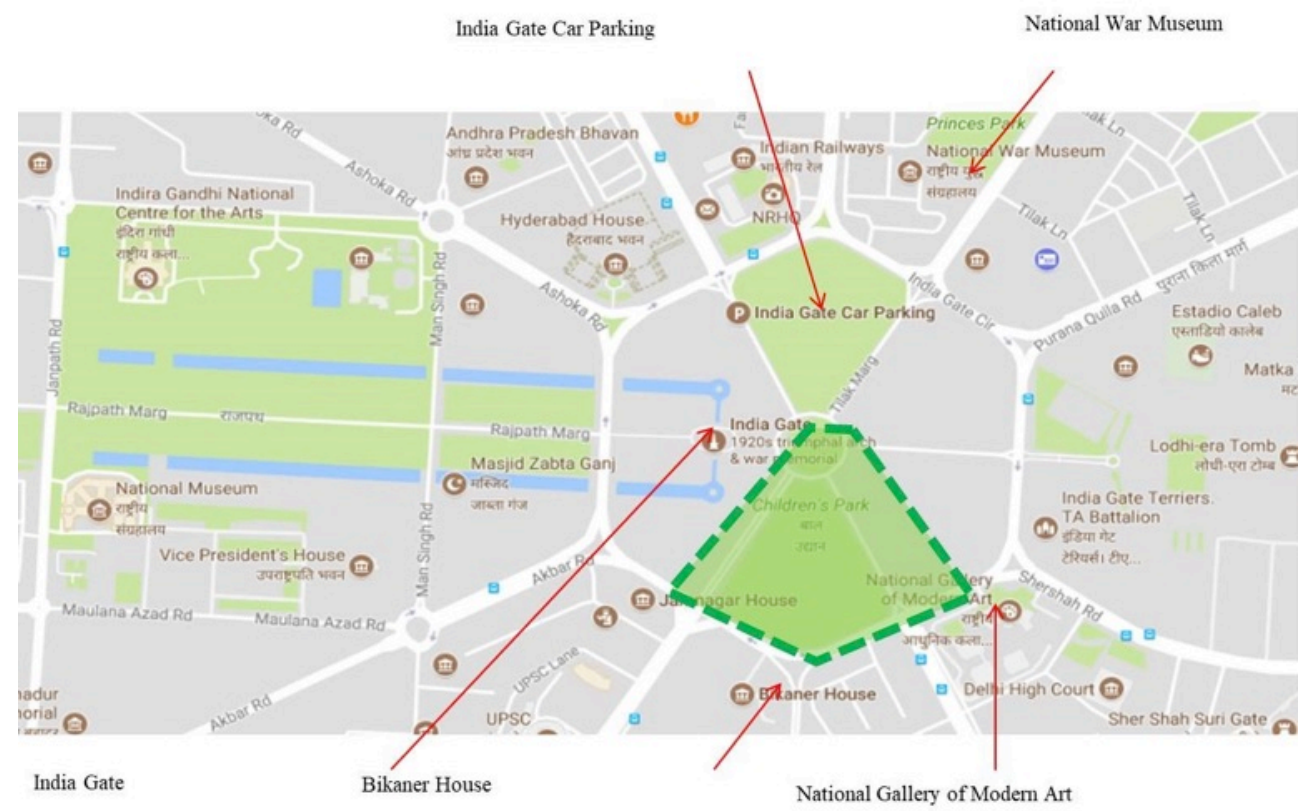

Figure 10. Location of Children Park (Source: Google).

The park is designed specifically for children and contains a variety of swings and a large area for children to enjoy, run around and play in; it is also enjoyed by families and is a popular place for morning walkers (Fig. II). Over time, new activities and facilities like a small open air theatre, a public library, new landscape features, fountains, new swings and public amenities have been added to the park, in addition to the carrying out of regular maintenance works. The park attracts visitors from the entire city as well as a large number of tourists.
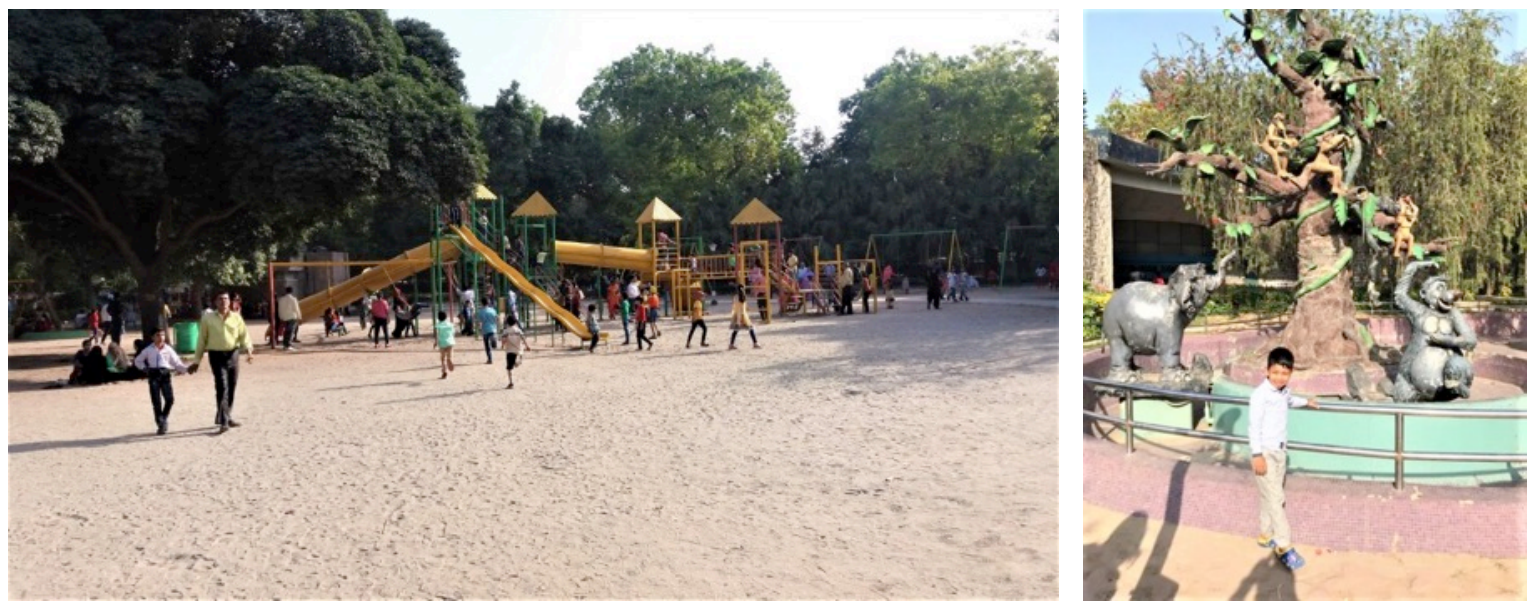

| 10 | The Journal of Public Space, 4(I), 2019 | ISSN 2206-9658

City Space Architecture / UN-Habitat 


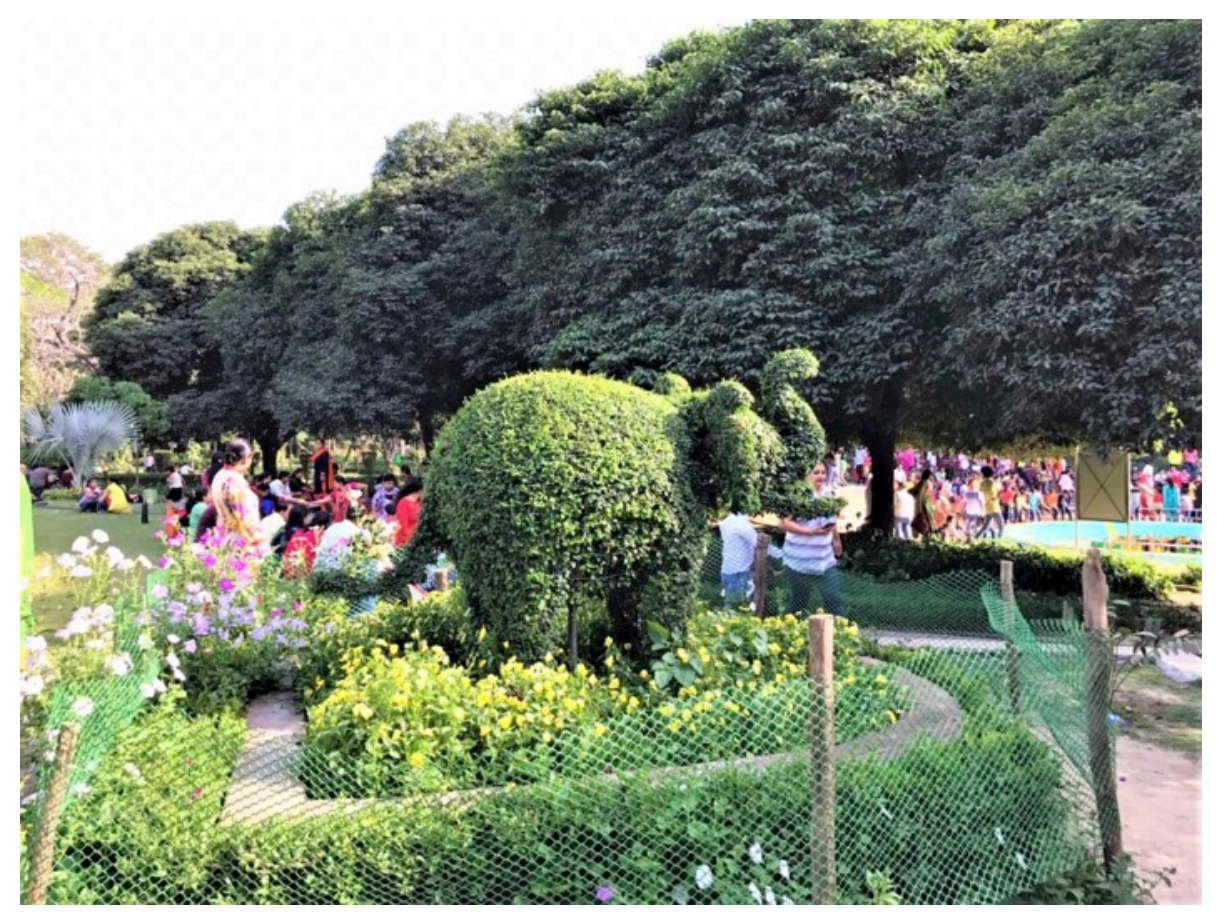

Figure II. Features and activities in Children Park.

\subsubsection{MDDA Park}

MDDA Park, also known as Rajpur Park is a neighbourhood park, planned and developed by the Mussorie Dehradun Development Agency (MDDA) on an area of 2.5 acres, which was opened for use in 2008. The park is nestled in the Kairwaan village of Rajpur and located along Rajpur road (Fig. 12). The park features a multi-levelled design which is in harmony with the mountains in the background (Fig. 13). The park has walking trails and benches with interactive games, and basic amenities such as drinking water, toilet facilities and a canteen area. People from surrounding neighbourhoods and residents and tourists city-wide visit the place. Users of the space include families, groups of students and couples. The park has a nominal entrance fee for safety reasons to deter undesirable/antisocial individuals from loitering around. It is open from 8 am until $6 \mathrm{pm}$ and receives an average footfall of around 350 people per day on weekdays, more users visit the park on weekends. 
Public space quality evaluation

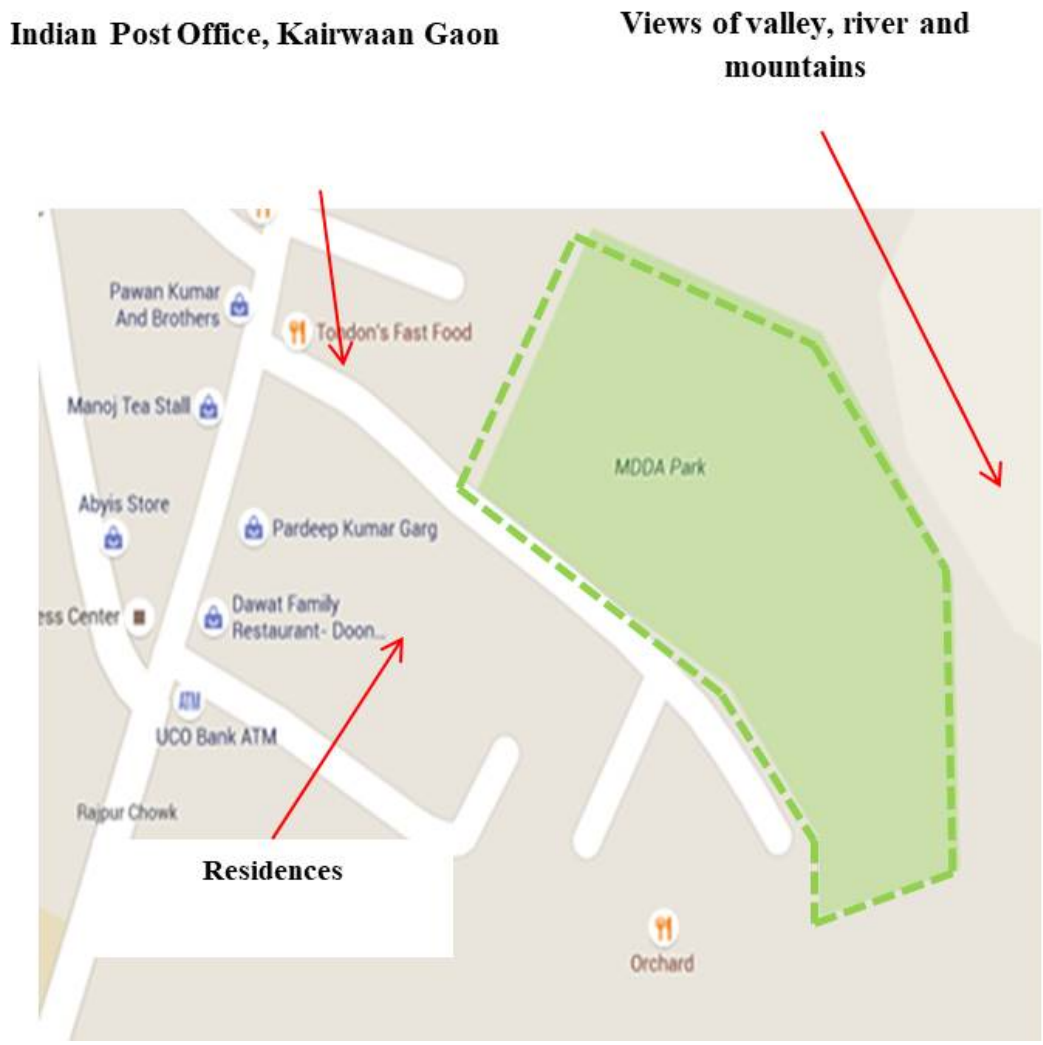

Figure 12. Map showing the location of MDDA Park (Source: Google).
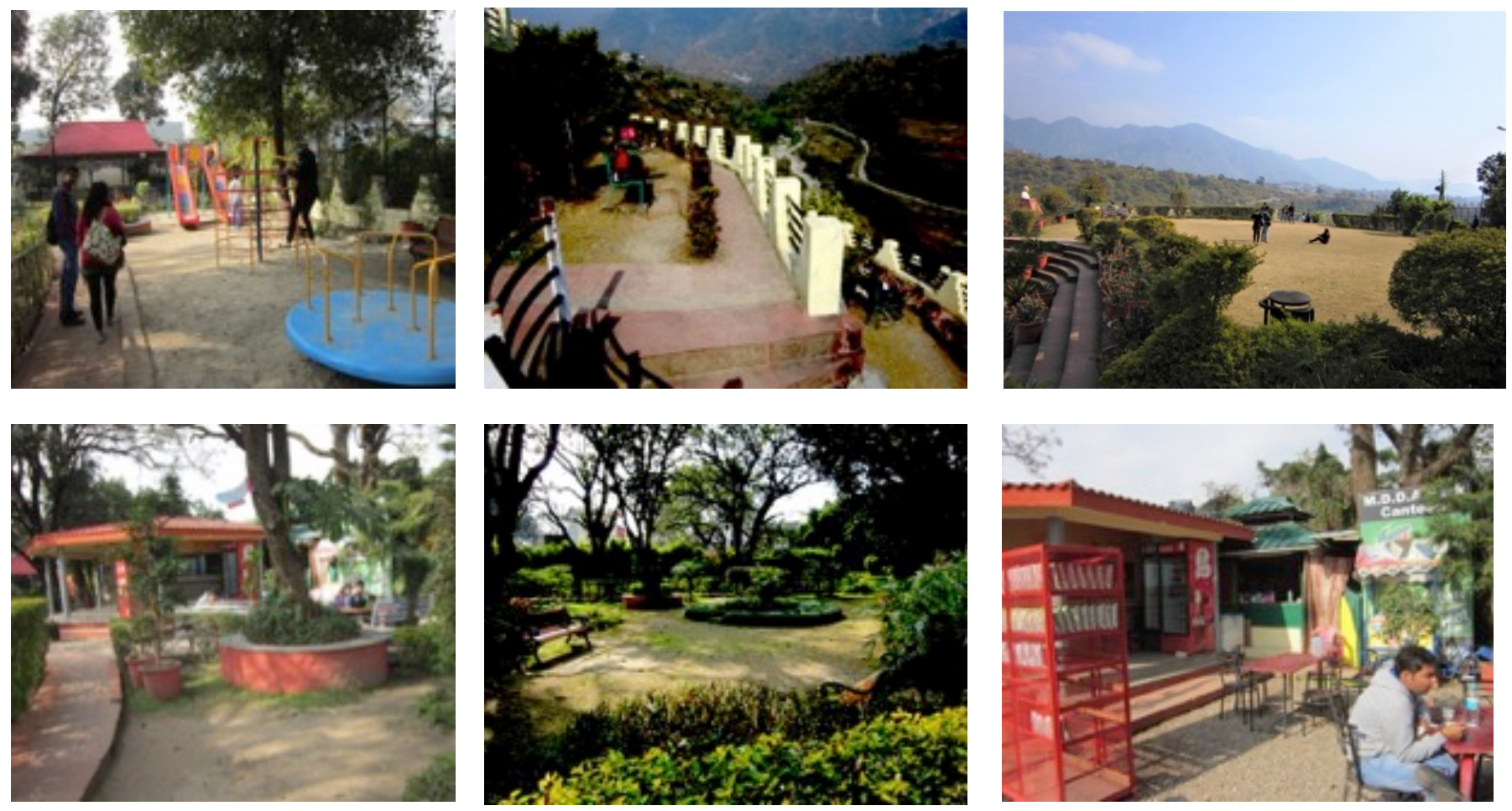

Figure 13. Images showing features and activities in MDDA Park. 


\subsubsection{Gandhi Park}

Gandhi Park is one of the oldest parks in Dehradun. It is one of the biggest public spaces covering an area of 12.1 acres, available to the people of the city. The park is located on Rajpur Road (Fig. 14), $400 \mathrm{~m}$ from the Dehradun Clock Tower and the Paltan Bazaar, a popular shopping area.

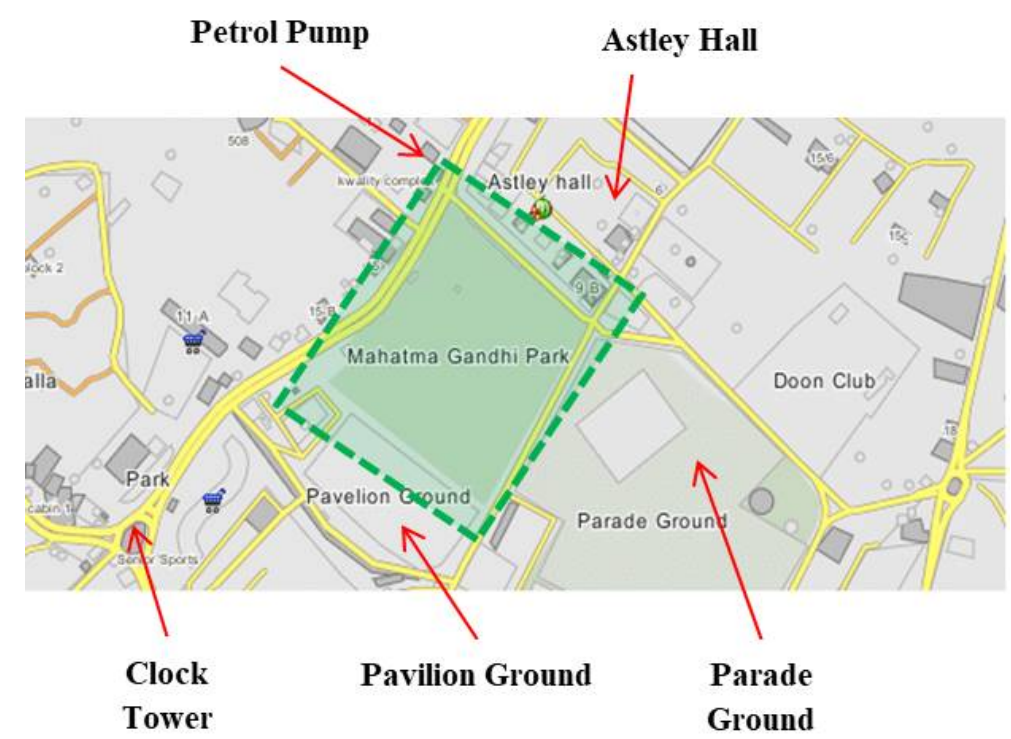

Figure 14. Map showing the location of Mahatma Gandhi Park (Source: Google)

On the east side of the tower lies Parade Ground, whereas towards the north lies the Astley Hall. The park has two entrances, the main entrance lies on the north-west side i.e. on Rajpur road. A petrol pump is also located at the park, on Rajpur road. Being popular shopping destinations, the nearby areas of the park provide people with the perfect area for relaxing and taking a break from mental and physical exertion. The park has green lawns where people sit, lie around and socialise (Fig. 15) in addition to a concrete track for joggers and early morning walkers. The park has two separate dedicated children's swing areas, one of which is a newly constructed Children's Park, which is gated and subject to an entrance fee (Fig. 16), whereas the other area is available for use by all children, free of charge. The park is open to users from 4 a.m. until 8 p.m. and has an average footfall of around I,500 people a day. Users of the space include families from across the city and people from nearby neighbourhoods, couples from more distant city areas and tourists. The space serves as a space for social gathering, public protests, strikes and health camps. 
Public space quality evaluation
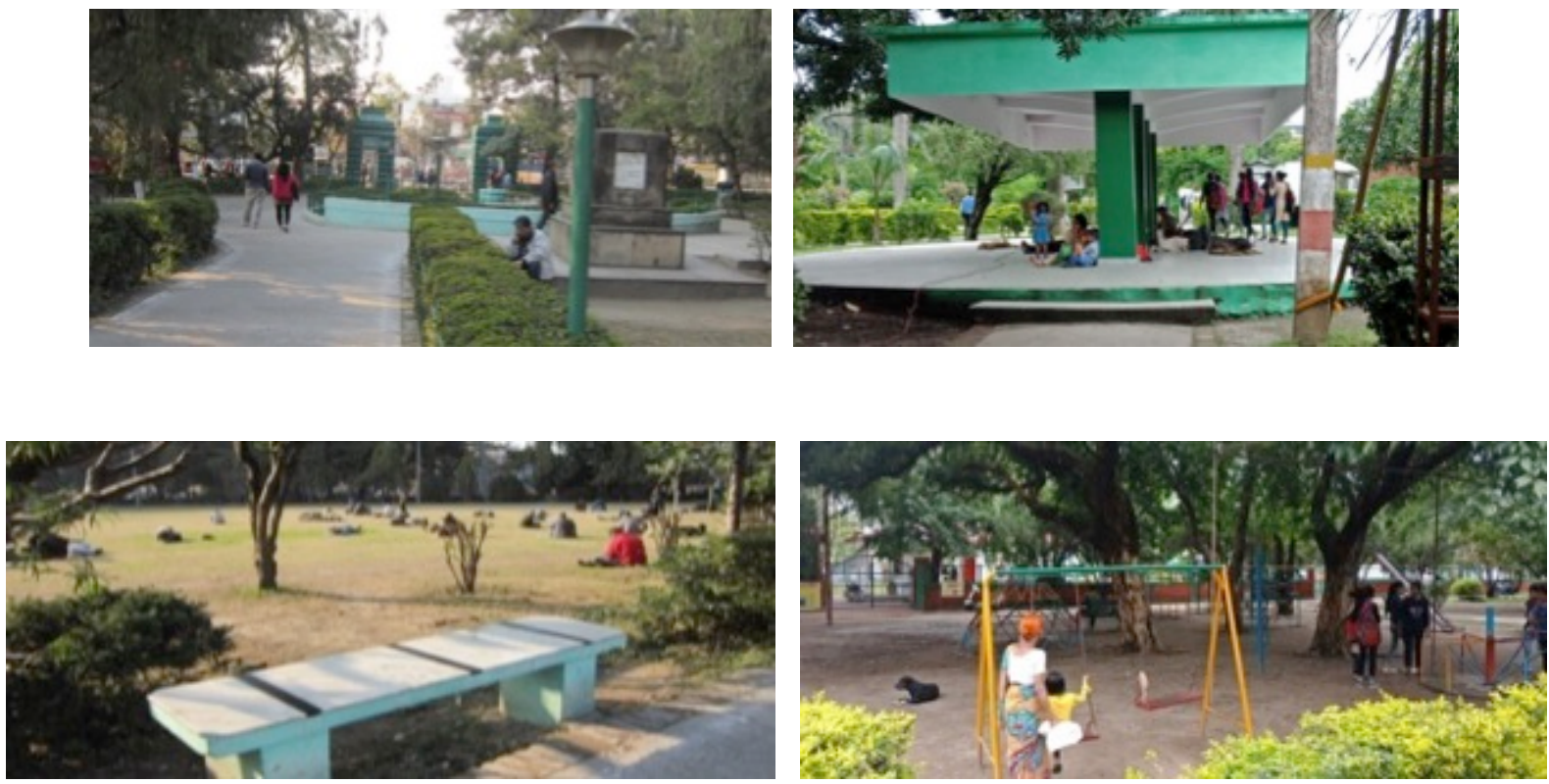

Figure 15. Features and activities in Mahatma Gandhi Park.

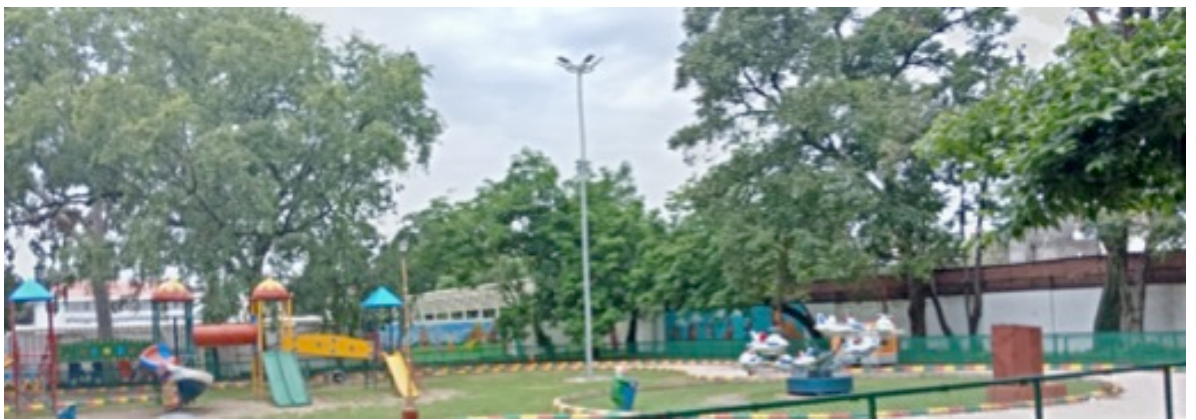

Figure 16. Newly developed Children's Park, part of Gandhi park under AMRUT Yojna.

The park is undergoing new, phased developments as part of the Atal Mission for Rejuvenation and Urban Transformation (AMRUT), an Indian Government scheme, under which; the Children's Park; a musical fountain; boating for children; a meditation and yoga centre; a children's play zone; flower beds; public utilities; an open amphitheatre; kiosks and a food court; a polyhouse; mounds; cycle tracks and jogging tracks are all proposed to be developed. Of these proposals, the Children's Park has been completed under the first phase of development and is now operational, and features recreational facilities for a fee, as mentioned earlier.

\section{Selected Study in Roorkee}

\section{I Ganga Park}

Ganga Park is a small park planned in an area of 0.5 acres, located in one corner of the city at the junction between two canals - the old Ganga Canal and the new one (the Upper Ganga Canal) (Fig. 17). When the new Ganga Canal was created, a triangular space was formed between the new and the old canals which boasts a beautiful view of 
the canals, with this in mind the area was planned as a park space. Nearby areas, the old city area and the civil lines area,do not have any parks to speak of except for two very small parks which lie along the canal in the civil line areas:but they are hardly used.

Surrounded by water on two sides and a road on the other side, Ganga Park is a much sought after public space for the residents of the city and small villages in the vicinity. The park provides several opportunities such as play areas and swings for children, spending time with family and friends, and views of the canal front from a short distance (Fig. 18). The park gets an average footfall of around 100 people daily and the people visiting the park are generally from lower and middle income groups and most of the users are either middle-aged males or females, young groups of boys or children from the nearby areas. No new developments or modifications have taken place in the park, except for regular maintenance and management works. However, new benches and dustbins are provided in the park from time to time. Recently the weekly market has been shifted from the civil lines area of the city to the road near the Ganga Park. This has led to increased usage and popularity of the space

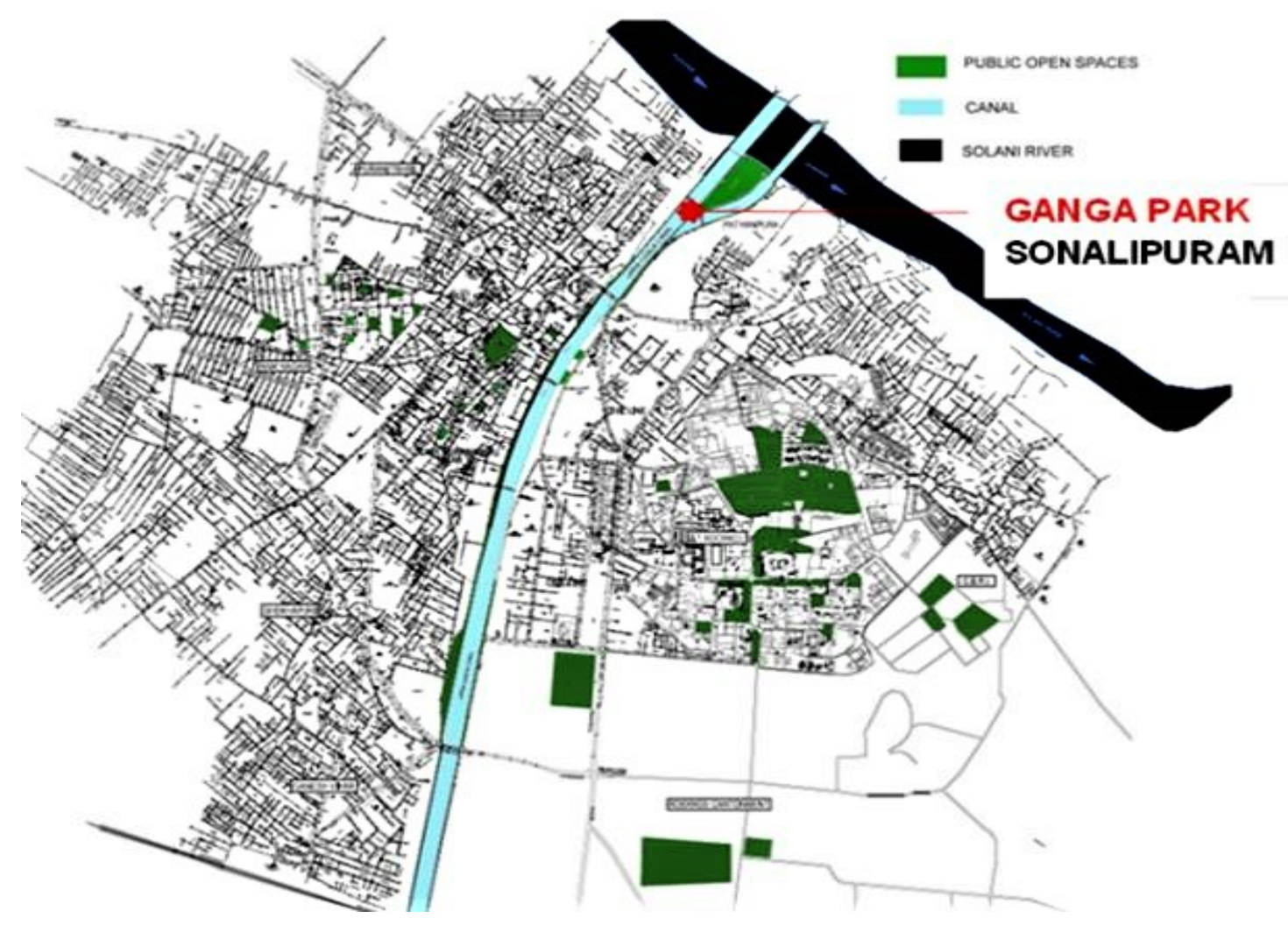

Figure 17. Map of Roorkee Showing Location of Ganga Park. 

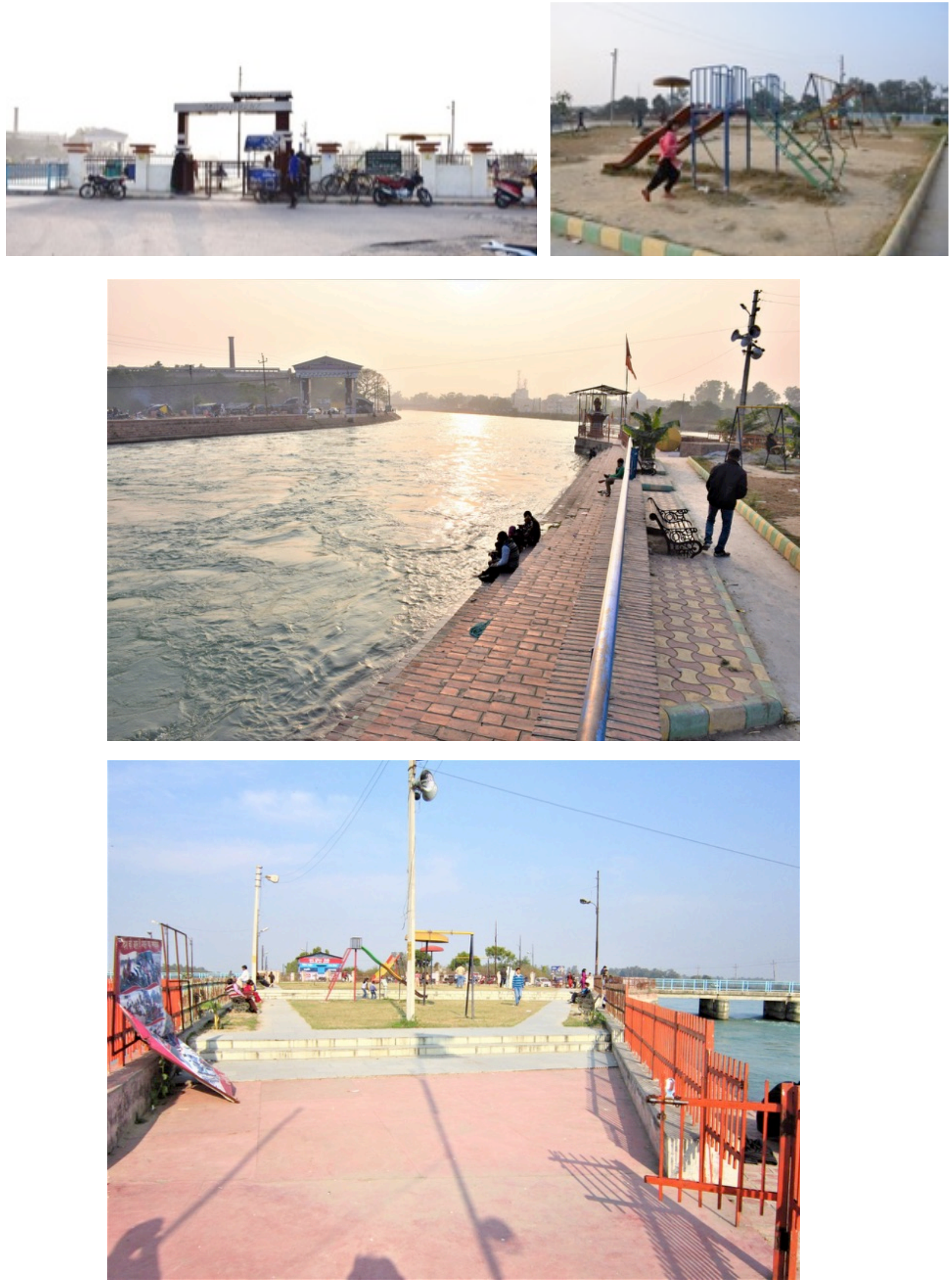

Figure 18. Images showing the features and activities in Ganga Park.

I 16 | The Journal of Public Space, 4(I), 2019| ISSN 2206-9658

City Space Architecture / UN-Habitat 


\section{Result}

After analysing the performance of parks according to the dimensions of quality using the PSQI the results are presented and discussed in detail and strategies to improve the respective spaces are proposed. The performance score for each dimension for the different parks as well as the overall performance of cities in terms of parks can be seen in Table 3 and its graphical representation in the form of a spider diagram is presented in Fig. 19; whereas a comparative performance of the parks studied in the three cities can be seen in Fig. 20.

Table 3: Dimension Score

Public Space Quality Index application on parks as public spaces in three different sized cities, i.e. Delhi (big city), Roorkee (small city) and Dehradun (medium sized city). The score for each dimension and the total score for public space achievement can be compared with different parks and focus areas can be highlighted for the application of management parameters

\begin{tabular}{|c|c|c|c|c|c|c|c|c|}
\hline \multirow{3}{*}{ Dimensions } & \multicolumn{8}{|c|}{ Score for Dimension of Quality in \% } \\
\hline & \multicolumn{5}{|l|}{ Delhi } & \multicolumn{2}{|c|}{ Dehradun } & \multirow{2}{*}{$\begin{array}{l}\begin{array}{l}\text { Roork } \\
\text { ee }\end{array} \\
\begin{array}{l}\text { Ganga } \\
\text { Park }\end{array}\end{array}$} \\
\hline & $\begin{array}{l}\text { Swarnajaya } \\
\text { nti Park }\end{array}$ & $\begin{array}{l}\text { ParshuRam } \\
\text { Park }\end{array}$ & $\begin{array}{l}\text { Central } \\
\text { Park }\end{array}$ & $\begin{array}{l}\text { Children } \\
\text { park }\end{array}$ & $\begin{array}{l}\text { Mahavir } \\
\text { park }\end{array}$ & MDDA & $\begin{array}{l}\text { Gandh } \\
\text { i park }\end{array}$ & \\
\hline Accessible and Linked & 91.03 & 91.16 & 96.77 & 78.71 & 89.41 & 87.02 & 62.45 & 74.63 \\
\hline Maintenance & 86.10 & 48.48 & 92.11 & 80.09 & 56.94 & 75.42 & 66.25 & 35.31 \\
\hline $\begin{array}{l}\text { Attractive and } \\
\text { Appealing }\end{array}$ & 70.73 & 51.48 & 72.50 & 81.71 & 49.63 & 61.05 & 58.00 & 42.70 \\
\hline Comfortable & 72.72 & 37.92 & 58.42 & 90.07 & 48.66 & 55.49 & 63.36 & 40.65 \\
\hline Inclusive & 84.31 & 100.00 & 94.94 & 87.04 & 98.93 & 56.27 & 67.95 & 94.65 \\
\hline Activities and Uses & 79.58 & 58.60 & 66.29 & 74.27 & 59.20 & 52.91 & 73.45 & 73.05 \\
\hline Purposefulness & 80.42 & 51.00 & 90.95 & 95.91 & 59.50 & 72.73 & 65.00 & 57.14 \\
\hline Safety and Security & 48.53 & 30.56 & 80.80 & 84.49 & 28.80 & 37.09 & 48.73 & 28.38 \\
\hline $\begin{array}{l}\text { Total Score of the Park } \\
\text { out of } 100\end{array}$ & 76.7 & 58.7 & 81.6 & 84 & 61.4 & 62.2 & 63.1 & 55.8 \\
\hline
\end{tabular}


Public space quality evaluation
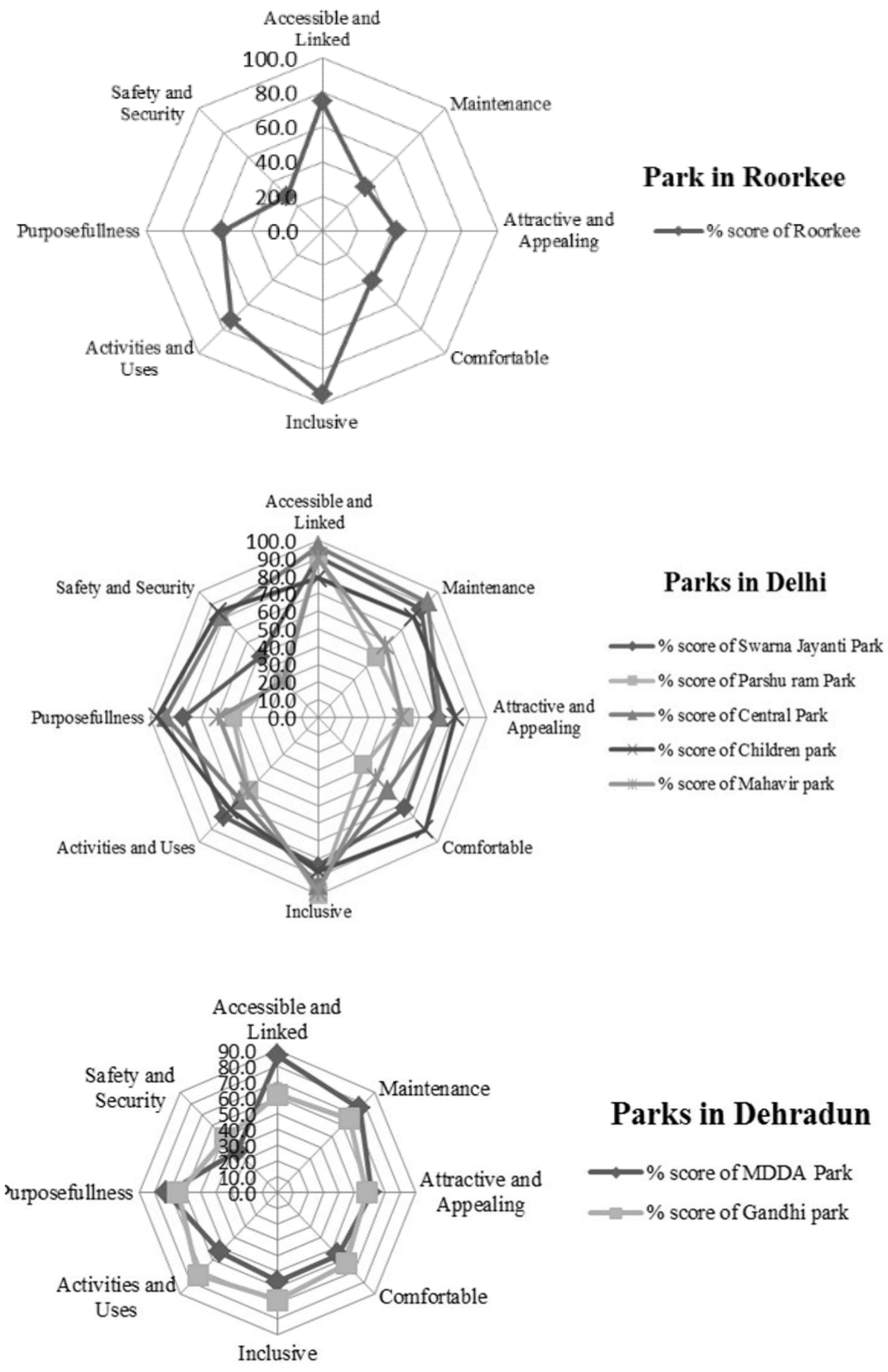

Figure 19. Performance of Public spaces (Parks) in Delhi, Dehradun and Roorkee on dimensions of quality.

I I 8 | The Journal of Public Space, 4(I), 2019 | ISSN 2206-9658

City Space Architecture / UN-Habitat 


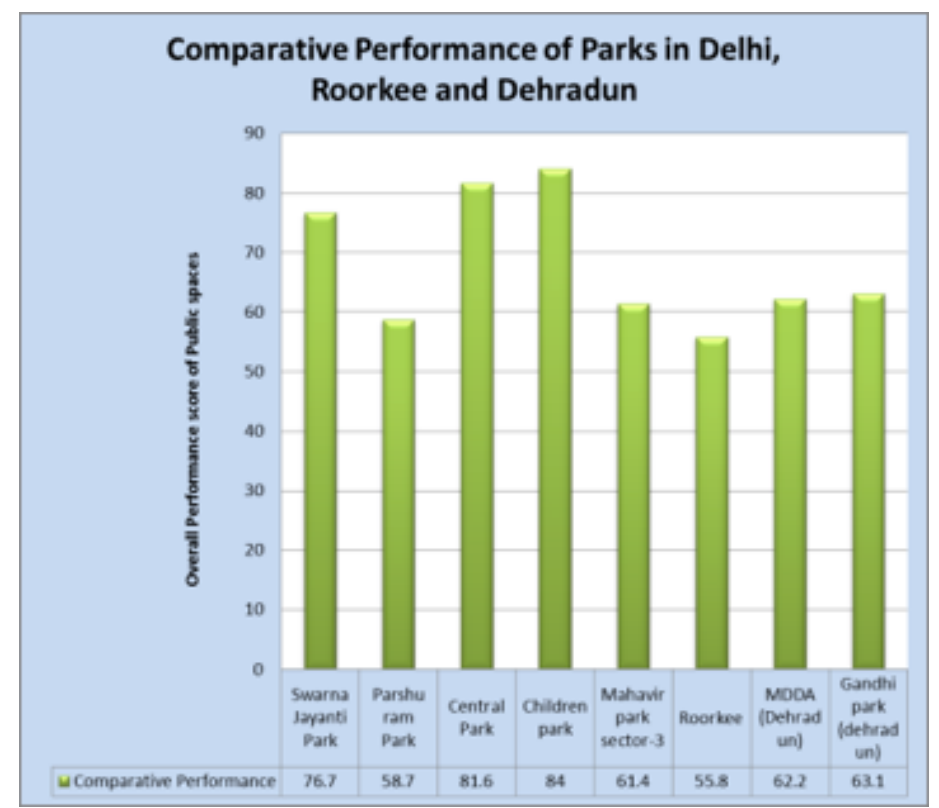

Figure 20. Comparative Performances of Public spaces (Parks) in Delhi, Dehradun and Roorkee.

From the table and the spider diagrams, it can be concluded that the parks spaces in Indian cities are generally accessible, linked and inclusive irrespective of the cities they are located in.

The major reasons for the poor state of parks are lack of maintenance, comfort, safety and security. It is further observed that these spaces do not encourage a variety of activities or modes of usage, and qualities relating to attractiveness and appeal are absent in neighbourhood parks. In addition, these parks do not appropriately utilise displayed public art and lack a clear and inviting aesthetic. Poor landscaping and illmaintained green areas further reduce the attractiveness of the parks. Some of these parks are not approachable i.e. they perform poorly in the dimension of accessibility which, over time, causes these parks to become hubs of illegal and antisocial activities resulting in permanent damage to the parks' image; a damaged reputation is then very difficult to repair.

Many times the damage is beyond repair and a park needs to be recreated using an entirely different concept. From the analysis of parks in all cities it is concluded that inappropriate arrangements for safety and security is the prime reason for the poor state of parks, followed by other reasons such as comfort, attractiveness and maintenance.

For example, the availability of basic amenities in parks like Swarn Jayanti Park leads to an increase in the use of the space for longer periods of time, which is also indirectly connected to the presence of the hawkers and vendors near the park: which in turn increase the active use of the space and make the park a more lively and inclusive space. However, a few of the parks are complete failures and at present are considered threatened areas wheretheyhave becomehubsof antisocial activities and are reduced to performing poorly across the dimensions of quality. After discussions with users from different cities it is further concluded that there is a need for some relaxing and 
recreational spaces in these cities, other than in the workplace or the home, spaces which are within easy reach of people. The individual performances of the parks as case studies in terms of dimensions of quality can be seen in Table. 3. From the table it is further interpreted that the parks in Delhi perform better compared to parks in Dehradun and Roorkee.

\section{I Accessibility and Linkage}

All parks generally score high in this dimension, but Gandhi Park in Dehradun received a total score of 62.4 on a scale of 100 . Hence this dimension needs to be focused on in the case of Gandhi Park such that its performance for the dimension of Accessible and Linked can be improved. From the detailed observational study of Gandhi Park it has been found that the park is located on a heavily trafficked road with no parking facilities, surrounded by busy commercial areas and absent of residences in the immediate neighbourhood. Therefore, it can be concluded that the park has accessibility and linkage issues. The main attributes that are responsible for a park's poor score for a dimension can be identified from the individual scoresfor the attributesin the dimension: which in the case of Gandhi Park are: visibility of the park from a distance, access to the space by walking and ease of movement in and around the park. Hence the performance of the space can be improved by strategizing the investment of funds and formulating policies that can improve its visual and pedestrian linkages, enhance public transport in its surrounding areas and provide parking facilities.

\subsection{Maintenance}

This dimension indicates the upkeep of the parks after they are put to use. Ganga Park in Roorkee received the lowest performance score for this dimension i.e. 35.3 per cent, whereas Mahavir Park in Delhi received an average score of 56.9 per cent. From the detailed observational study it was found that Ganga Park is poorly maintained, no regular maintenance or management regime is followed for the upkeep of the park and efforts are limited to cleaning and sweeping. Furthermore, the maintenance cost of the park is also very low and not in accordance with the CPWD specifications followed by cities throughout India. The park is mostly used by neighbouring people from lower income groups, therefore poor surroundings also influencethe state of park. A daily market operates in the surrounding areas, which contributed to the space's faded aura. Hence, strategies to improve the dimension of maintenance for Ganga Park should be such that regular maintenance and cleaning schedules can be implemented under the strict supervision of the authority. There is also a need to regularise vendors and markets in the surrounding area, such that the visibility of and approach to the space can also be improved. Further arrangements for alternate sources of funding must be made and these finances and other resources should not be used in the wasted interest of politicians but should be as per maintenance needs.

\subsection{Attractiveness and appeal}

From the results of the analysis it can be stated that the parks in small and medium-size cities as well as small parks in big cities score average or below average for the dimension of attractiveness and appeal, regardless of the context they are located in. In the present study MDDA Park and Gandhi Park inthe medium-sized city Dehradun 
received a score of 61.05 per cent and 58 per cent respectively. Whereas the performance of Ganga Park in Roorkee, a small city,received a score of 42.70 per cent and the performance scoresfor Parshuram Park and Mahavir Park,located in big cities,were 51.48 per cent and 49.63 per cent respectively. From the detailed observational studies and discussion with the users and authorities; it was found that the poor state of parks in the dimension of attractiveness and appeal is due to lack of professional input across the board: at the time of planning and design, construction and use. Similarly, the presence of rules for the use of space, their strict implementation and penalties for their violation are equally important in order that the condition of a park can be maintained to meetcertain standards. Further maintenance bodies and the establishment of maintenance modes are equally important such that the line of responsibilities for maintenance and management are clear and are answerable for the poorstate of any space. In this case then, strategies should be such that the strict implementation of rules of conduct and upkeep are ensured and at the same time that the appropriate professional inputs are taken into consideration. Further practice of contracting out or employing a rotating team can be used in cases where the condition of parks is very poor; adopting these kinds of practices will ensure that the people involved in the management of parks are made accoutable. Policise can also be formulated in such a way that the space is adopted for maintenance and management by the local RWA and by other organizations under corporate social responsibility; this practice will lead to an improvement in the condition of the park.

\subsection{Comfort}

Out of the case studies taken up; five parks scored below average for the dimension of comfort, Parshuram Park scored the least, followed by Ganga Park, Mahavir Park and MDDA Park. The attributes associated with this dimension are the presence of comfortable sitting areas, the presence and condition of public facilities and sheltered areas, the presence of signage and the provision of parking facilities, and a buffer from the nuisance of traffic. From the detailed observations and discussion with the respective stakeholders, it has been found that the poor performance of a park in the comfort dimension is a result of a lack of professional inputs during the planning, design and construction phases of the facility. Planning without consideration for basic standards is another reason for missing comfort in these spaces. Furthermore,an absence of basic amenities andthe presence of antisocial elements makes the spaces even more uncomfortable forchildren and women wishing to use them. Sometimes the attitudes of certain users also make a space uncomfortable for other users. Therefore, appropriate strategies regarding involving professionals at every stage of public space projects, from planning to construction, and its management and maintenance thereafter needto be adopted. Public open spaces can be made more comfortable if theyare properly designed and active and passive recreational spaces are segregated within the park itself, so that different user groups can enjoy activities of their choice without any hindrance. Certain design and security measures can also be adopted such that the spaces do not becomehubsof antisocial activities and are instead comfortable to occupy by a range of users. 


\subsection{Inclusiveness}

All the parks perform quite well in the dimension of inclusiveness, apart from MDDA Park. In all the studies there is no restriction on entry to the park, besides some security measures, but in the case of MDDA Park a paid-entrance system is enforced, which prevents certain sections of society from using the public space. In many cases it was found that the entrances to many parks are controlled by specified timings and that some are closed on certain days for weekly maintenance and management. On the one hand these are the kinds of public spaces that users require on a daily basis, on the other hand, their maintenance and management is crucial, such that they are able to meet the daily needs of the users. Therefore, there is a need for strategies/ guidelines that ensure that public spacesare accessible to all prospective users, irrespective ofage, race, class, gender or physical abilities. The control of a space according to specific timings needs to be rationalised so that it can be used by the maximum number of users possible. Also, a public space can be considered more inclusive when the internal spaces of the park can serve different user groups in such a way that all are provided for without the need to interfere in each other's interests; a balanced that is achieved through the careful design of active and passive spaces.

\subsection{Activities and uses}

All the spaces perform very well for this dimension as even just the existence of such public spaces givespeople hope;knowing that they have other spaces to go to spend time outside their homes and workplacesprovides them withmore options for socialising and relaxing. Options for multiple activities in a space adds to the richness in the performance of that space, such diverse activites could include; walking, socialising, being involved in activities associated with physical activity, different sports and games, children's play, options for family outings or educational visits, options for events and gatherings and opportunities to engage with the fauna and flora.Design and management strategies should be such that they aid in ensuring that these activities are carried out without cause for conflict and that each of the users is able to be involved in activities which they find value in and can feel connected to.

\subsection{Purposefulness}

Public spaces must meet the purposes for which they are created, but from the studies it is apparent that Parshuram Park, Ganga Park and Mahavir Park perform low across this dimension. The attributes responsible for a public space's performancein this dimension are related to the suitability of the layout and design and the ambience of a space. These two attributes can only be incorporated into a public spacewhen the layout and design decisions regarding a space take professional inputs into consideration, such that the finalised space is in a position to effectively respond to its own specific context and in addition, all aspects relating to the needs and expectations of its prospective users. This kind of approach will not only result in a facility that fulfills its users' requirements and expectations but such spaces become the most loved and used assets in cities and towns: never losing their significance in people's lives or place in their city as a whole. 


\subsection{Safety and security}

Any space must perform high in the dimension of safety and security as only then will it be well managed. Most of the parks are currently performing extremely poorly in this dimension, and only Children Park and Central Park are currently able to meet the need for security in public space. Often, the lack in security and safety results in the complete failure of public spaces; the non-implementation and violation of rules is one of the main reasons for lack of safety and security in the presence of antisocial activities. Hence, while making strategies for safety and security in public spaces, it must be ensured that all the attributes mentioned as part of the safety and security dimension are taken into consideration when planning a new public space or redeveloping an existing public space. These attributes are; the presence of adequate light; adequate surveillance measures and security arrangements; the provision of an information/ complaint centre; and strict policies on the entry of animals, criminal activities and antisocial components. Therefore strategies ensuring regulation of use, implementation of rules and penalties and adequate surveillance measures which improve visibility must be worked out. The authority responsible for the maintenance and management of a park should also formulate a committee for monitoring the performance of public space from time to time and address the problems and issues that come up.

\section{Conclusion}

Inspite of the significance and benefits of public spaces in cities being recognised the world over, the research being done on the quality attributes of successful public spaces and the number of projects being undertaken for the improvement of public spaces in developed countries, there are currently no such concerted efforts taking place in India. Moreover, there are significant variations in the types, sizes and quality of public spaces, as well as, differences in their usage across cities in India. This diversity is observed both in contrasting different sized cities and indeed spaces within a city, a diversity which necessitates a study of public spaces in different cities in India to identify the attributes/criteria responsible for good quality of public spaces. The proposed framework, led by the development of the PSQI helps in evaluating and highlighting the dimensions of quality currently receiving low scores that are signifiers of the poor performance of public spaces in Indian cities. This can help in formulating strategies that are focused and which can effectively target specific problems. From the analytical study of the different parks in the selected cities it is evident that parks in medium-sized cities and small cities and small parks in large cities don't perform well across the majority of the dimensions of quality outlined here. This current state of affairs is the result of; low accessibility and linkage; a lack of professional input in the planning and design stage and subsequent management of public spaces; a lack of funds and their inappropriate utilisation that fails to focus at on the actual problems; inappropriate maintenance routines; loopholes in the rules and regulations relating to uses/activities and encroachments; deficiencies in the security measures adopted; an absence of clearly defined responsibilities; and lack of subsequent ongoing monitoring and control of the unfolding situation. Each public space will differ from the others due to its typology and context and will perform differently, so accordingly, the strategies adopted for improving performance will also differ; but the attributes/dimensions associated with quality are the same for any type of public space and the methodology suggested for 
evaluation is relevant to all. Though the present study only focuses on one typology of public spaces i.e. parks, there are various other types of public spaces and parameters/attributes under several dimensions that can be further tested for other spaces, or indeed new parameters/attributes that could be developed using a similar framework. As the proposed framework is easy to understand and implement, it can be utilised by planning, development and management agencies during the initial stages of planning new public spaces as well as during the evaluation process and improvement of existing public spaces. Hence providing strategies for public spaces, based on an evaluation framework can result in better managed and more successful public spaces.

\section{References}

Baycan-Levent, T., Nijkamp, P. (2008) "7 Frequently Asked Questions (FAQs) in Urban Planning", Studies in Regional Science, 38:2, 35I-37I.

Beer, A. R., Delshammar, T., \& Schildwacht, P. (2003). A changing understanding of the role of green space in high-density housing: A European perspective. Built Environment, 29(2), I32-I43.

Cackowski, J. M., \&Nasar, J. L. (2003). The restorative effects of roadside vegetation implications for automobile driver anger and frustration. Environment and Behaviour, 35(6), 736-75I.

Carmona, M., \& De Magalhaes, C. (2006). Public space management: present and potential. Journal of Environmental Planning and Management, 49(I), 75-99.

Carmona, M. (2010). Contemporary public space, part two: classification. Journal of Urban Design, I5(2), I57-I73.

Carr, S. (1992). Public space. Cambridge University Press.

Celik, Z., Favro, D., \& Ingersoll, R. (1996). Streets: critical perspectives on public space. Univ of California Press.

Chiesura, A. (2004). The role of urban parks for the sustainable city. Landscape and urban planning, 68(I), 129-138.

Dempsey, N., \& Burton, M. (2012). Defining place-keeping: The long-term management of public spaces. Urban Forestry \& Urban Greening, I I (I), II-20.

De Sousa, C. A. (2003). Turning brownfields into green space in the City of Toronto. Landscape and urban planning, 62(4), $181-198$.

Emmanuel, R. (1997). Urban vegetational change as an indicator of demographic trends in cities: the case of Detroit. Environment and Planning B, 24, 4I5-426.

Ewing, R., \& Clemente, O. (2013). Measuring urban design: Metrics for livable places. Island Press.

Ewing, R., \& Handy, S. (2009). Measuring the unmeasurable: urban design qualities related to walkability. Journal of Urban design, I 4(I), 65-84.

Forsyth, A., Musacchio, L., \& Fitzgerald, F. (2005). Designing small parks: a manual for addressing social and ecological concerns. John Wiley \& Sons.

Fyfe, N. (1998). Images of the Street. London and New York: Routledge.

Gehl, J. (1987). Life between Buildings. New York: Van Nostrand-Reinhold.

Hartig, T., Mang, M., \& Evans, G. W. (199I). Restorative effects of natural environment experiences. Environment and behaviour, 23(I), 3-26. 
Iverson, L. R., \& Cook, E. A. (2000). Urban forests cover of the Chicago region and its relation to household density and income. Urban Ecosystems, 4(2), 105-124.

Jacob, A. (1993). Great streets. Massachusetts Institute of Technology, USA.

Jim, C. Y. (2004). Green-space preservation and allocation for sustainable greening of compact cities. Cities, 2 I (4), 3I I-320.

Jacobs, J. (1992). The death and life of great American cities. 196I. New York: Vintage.

Kaplan, R. (200I). The nature of the view from home psychological benefits. Environment and behaviour, 33(4), 507-542

Keil, R. (2003). Urban Political Ecologyl. Urban Geography, 24(8), 723-738.

Korpela, K. M., Hartig, T., Kaiser, F. G., \& Fuhrer, U. (200I). Restorative experience and selfregulation in favourite places. Environment and behaviour, 33(4), 572-589.

Kuo, F. E., \& Sullivan, W. C. (200I). Environment and crime in the inner city does vegetation reduce crime?. Environment and behaviour, 33(3), 343-367.

Kuo, F. E., \& Sullivan, W. C. (200I). Aggression and violence in the inner city effects of environment via mental fatigue. Environment and behavior,33(4), 543-57I.

Loukaitou-Sideris, A., \&Ehrenfeucht, R. (2009). Sidewalks: Conflict and negotiation over public space. MIT Press.

Low, S. M. (2010). On the plaza: The politics of public space and culture. University of Texas Press.

Low, S., \& Smith, N. (Eds.). (20I3). The politics of public space. Routledge.

Luttik, J. (2000). The value of trees, water and open space as reflected by house prices in the Netherlands. Landscape and urban planning, 48(3), I6I-167.

Madanipour, A. (1996). Design of urban space: An inquiry into a socio-spatial process. John Wiley \& Son Ltd.

Madanipour, A. (1999). Why are the design and development of public spaces significant for cities? Environment and Planning B, 26, 879-892.

Marcus, C. C., \& Francis, C. (Eds.). (1997). People places: Design guidelines for urban open space. John Wiley \& Sons.

Mehta, V. (2013). The street: a quintessential social public space. Routledge.

Morancho, A. B. (2003). A hedonic valuation of urban green areas. Landscape and urban planning, 66(I), 35-4I.

Moudon, A. V. (Ed.). (1987). Public streets for public use. New York: Van Nostrand Reinhold. 
Pauleit, S., Slinn, P., Handley, J., \& Lindley, S. (2003). Promoting the Natural Green structure of Towns and Cities: English Nature's" Accessible Natural Green space Standards" Model. Built Environment (1978-), I57-I70.

Praliya, S, Pushplata, 2012. Issues of Public Spaces in Small Cities in India: Case study Roorkee. Fourth IJAS Conference At Cambridge, USA, 27 - 3IMay 2012.

Praliya, S., Pushplata, 2016. Public Open Spaces in Indian Small Cities: A case of Roorkee. SPACE, 20 (3-4), pp.57-70.

Project for Public Spaces (Ed.). (2000). How to turn a place around: a handbook for creating successful public spaces. Project for Public Spaces Incorporated.

Robbins, P., Polderman, A., \&Birkenholtz, T. (200I). Lawns and toxins: an ecology of the city. Cities, I8(6), 369-380.

Rodenburg, C., Baycan-Levent, T., van Leeuwen, E., \&Nijkamp, P. (200I). Urban economic indicators for green development in cities. Greener management International, 200I(36), 104-II9.

Rossman, B. B., \&Ulehla, Z. J. (1977). Psychological Reward Values Associated with Wilderness Use A Functional-Reinforcement Approach. Environment and Behaviour, 9(I), 4I-66.

Smith, T., Nelischer, M., \& Perkins, N. (1997). Quality of an urban community: a framework for understanding the relationship between quality and physical form. Landscape and Urban Planning, 39(2), 229-24I.

Stanford, A. (1978). On Streets. Cambrigde, Massachusetts: The MIT Press

Swanwick, C., Dunnett, N., \& Woolley, H. (2003). Nature, role and value of green space in towns and cities: An overview. Built Environment, 29(2), 94-106.

Swyngedouw, E., \&Heynen, N. C. (2010). Urban political ecology, justice and the politics of scale. The Blackwell City Reader, 79.

Taylor, A. F., Wiley, A., Kuo, F. E., \& Sullivan, W. C. (1998). Growing up in the inner city green spaces as places to grow. Environment and Behaviour, 30(I), 3-27.

Ulrich, R. S. (198I). Natural versus urban scenes some psychophysiological effects. Environment and behaviour, 13(5), 523-556.

Ulrich, R. (1984). View through a window may influence recovery. Science, 224(4647), 224-225.

Whyte, W. H. (1980). The social life of small urban spaces. 